\title{
ADHESION MEASUREMENT OF THIN FILMS
}

\author{
K. L. MITTAL \\ MHV System Products Assurance, IBM Corporation, Poughkeepsie, N.Y. 12602, U.S.A.
}

(Received August 18,1975)

\begin{abstract}
A critical and comprehensive review of the various methods for the measurement of adhesion of thin films is presented. Emphasis has been placed on the techniques used for thin films $(<1 \mu \mathrm{m})$ but consideration has also been extended to methods which have proved successful in case of relatively thicker coatings and are potentially applicable in the study of thin films. Most of the methods catalogued in this review have been harnessed in measuring the adhesion of thin evaporated or sputtered metallic films on an assortment of substrates; the literature references to the study of thin polymeric films are extremely meager.

The methods of determination of adhesion are discussed under three headings: Nucleation Methods, Mechanical Methods and Miscellaneous Techniques. Furthermore, the mechanical methods are categorized depending upon the mode of application of the force to disrupt the interface. Although the emphasis is on the quantitative methods of measuring adhesion, but for completeness qualitative as well as the methods which are still in a state of infancy have been included.

Requirements for the ideal adhesion test are outlined and, apparently, there does not exist any test which fulfils all the virtues. Many of the techniques may not provide absolute quantitative values of adhesion strength but these can profitably be used to follow relative changes in adhesion strength due to process variables, ageing weathering, etc.

The principle, merits, potentialities, and limitations of each technique are outlined, and the difficulties associated with measuring adhesion strengths and their relationship to "basic adhesion" are discussed.
\end{abstract}

\section{INTRODUCTION}

In recent years, the use of thin films $(<1 \mu \mathrm{m})$ has proliferated in a variety of electronic, engineering, optical, biomedical, nuclear, space, and other applications. This wide spread use is attributed to the fact that, quite often, materials in monolithic form are not suitable for the diverse and special requirements, and thin films provide the requisite answer. Thin films are used for many and varied purposes: to provide resistance to abrasion, erosion, corrosion, galling, tarnish, wear, radiation damage, or high temperature oxidation; to reduce friction or electrical resistance, provide lubrication, prevent sticking; and also to provide special magnetic or dielectric properties.

Whatever their intended use may be, the properties, structure, functional characteristics, and performance all depend, inter alia, on adhesion between the coating and the substrate. Below are cataloged some of the prime reasons emphasizing the importance of adhesion of thin filns.

1) Adhesion is very important in thin film technology because the thin films (usually $<1 \mu \mathrm{m}$ and in some applications of the order of $50 \mathrm{~nm}$ ) are so fragile that these must be supported by more substantial substrates and the degree to which the film can share the strength of the substrate depends upon the adhesion between the two.

2) Adhesion is very important in determining the durability of thin film devices, for example, in microelectronic circuits.

3) Adhesion plays an important role in governing the kinetics of the growth and structure of the films (formed by vacuum deposition, for example), with the result that performance of thin films is dictated by adhesion forces. Film structure will be aggregated whenever the cohesional energy exceeds the energy of adhesion. This dependence of film integrity upon adhesion forces is not only important from the viewpoint of performance of such films but it also has a basic scientific import.

4) The durability and longevity of thin films are largely dependent upon their adhesion to the substrate since this determines the ease of removal.

5) It is highly desirable that films should be capable of being cleaned and polished, particularly where these are used for front surface reflectors and it means they should have good adhesion in addition to other factors like resistance to corrosion.

6) Wear is intimately related to the extent of adhesion of thin film to the substrates; if the adhesion is poor, the film will wear off quite rapidly. 
7) Adhesion is a fundamental parameter in surface chemistry and physics because it depends directly on interatomic and intermolecular forces. Thin films should provide an ideal situation because it is in such systems that conditions of true interfacial contact can most nearly be attained. For example, a film deposited on a clean substrate under high vacuum conditions faithfully contours all surface irregularities and imperfections and almost perfect contact between the film and the substrate should be readily obtained.

8) Good adhesion of thin films, used as protective overcoats, is very vital for the environmental protection (e.g. protection from corrosion) of the substrates. If the adhesion is poor, the extent of deterioration of the substrates by environmental factors (humidity, corrosive gases, etc.) is greatly accelerated.

9) The metallization of polymeric materials reduces considerably the gas permeability of the polymeric, and this reduction is strongly influenced by the adhesion between the metal and the polymer.

Henderson ${ }^{1}$ has discussed the importance of adhesion in electronics.

Thin films are deposited by a variety of techniques which are well described in many monographs and technical papers. The adhesion of thin films is affected by substrate cleaning, procedure, the rate of deposition, the film thickness, the type of substrate, the substrate temperature, the purity of source material, pressure in the evaporator during deposition, glow discharge ambients etc. In order to quantify the effects of these variables, the necessity for having reliable techniques for measuring adhesion is quite manifest.

So the purpose of this review is to critically examine the various methods of measurement of adhesion which have been tried successfully, or with partial success in the study of thin films on various substrates. Let it be pointed out at the outset that most of the adhesion measurements have been made using evaporated or sputtered metallic films onto glass, metals, or oxide substrates. Only a meager amount of published work is available on the adhesion measurement of thin polymeric films. The viscoelastic nature of polymeric films dictates that difficulties are inevitable in employing some of the techniques used in the case of thin metallic films, and the need to explore the possibilities of other potential techniques is obvious. Recently, there has been a resurgence of interest in the application of thin polymeric films to various substrates, so the necessity of good and controlled adhesion in such systems cannot be overemphasized.

\section{PREVIOUS REVIEWS}

Before presenting a comprehensive account of the methods of measurement of adhesion, it is in order to take due cognizance of the reviews published earlier on a similar topic. Weaver ${ }^{2}$ in 1958 made a survey of the adhesion forces and their influence on the structure and properties of thin evaporated films and he has reviewed the practical methods of measuring film adhesion and durability. It should be pointed out that this review has been very restrictive in coverage of the methods of measurement and emphasis has been on the thin evaporated films only. In a subsequent article by Weaver ${ }^{3}$ in 1965 , again the study of adhesion of thin evaporated metal films was accentuated and only a few techniques of measuring adhesion were discussed.

Davies and Whittaker ${ }^{4}$ in 1967 made a comprehensive survey of the methods of testing the adhesion of metal coatings (such as electroplates) to metals. This review presents a good coverage of the melhods of measuring adhesion but is mainly confined to metal coatings deposited primarily by electrolytic means. Some of the techniques of measuring adhesion are not referred to or are mentioned only in passing. Furthermore, the units in which adhesion values have been expressed are not consistent, i.e., widely different units have been used and this hinders an easy comparison of different methods as used by different investigators. More recently, Williams ${ }^{5}$ has discussed the adhesion of thin vacuum deposited films (mainly metallic) and he has focussed primarily on the factors controlling the adhesion of such films; only a peripheral account of the techniques of measuring adhesion is presented.

Bullett and Prosser ${ }^{6}$ have presented an exhaustive exposition of the methods of measuring adhesion but their emphasis has been on paints or coatings which are far thicker $(\sim 25 \mu \mathrm{m})$ than the thin films. Some of the methods which are viable in the field of paints and coatings may not be suitable for thin films. This is an excellent review for workers in the field of paints and coatings, and may not be too pertinent to thin film work because some of the techniques applicable for thin films have been excluded. Campbell ${ }^{7}$ has presented nicely the techniques suitable for measuring adhesion of thin films, but some of the techniques have not been discussed in adequate detail. This review should be particularly 
consulted for nucleation methods of determining adhesion.

More recently, Mittal ${ }^{8}$ has presented a comprehensive account of the techniques for measuring adhesion of electrodeposited coatings; many of these techniques are applicable to thin films also. Chapman ${ }^{9}$, and Weaver ${ }^{10}$ have discussed summarily some of the techniques for measuring adhesion of thin films, and they have pointed out the inherent difficulties involved in this area.

After this background information, it is appropriate to enumerate the salient features of the present review; these are as follows:

1) An attempt has been made to present as comprehensive and general account as possible; the main points of each technique are fully discussed.

2) All the fully developed, partly developed, and the promising methods in embryonic state have been included. The merits and demerits of each are fully discussed.

3) The values of adhesion are all expressed in SI units. i.e., in Newton per squaremeter $\left(\mathrm{N} \mathrm{m}^{-2}\right)$. The conversion factors from one system of units to another are given in the Appendix. Other quantities have also been expressed in SI units.

4) Various kinds of films and substrates have been discussed, i.e., the review is not restricted to any particular type of film or substrate.

5) Wherever possible, the thickness and other important parameters of films are explicitly mentioned.

6) As the purpose of this review is to discuss exclusively the techniques for measuring adhesion, the techniques of depositing thin films or the factors affecting adhesion of deposited films are not discussed.

\section{WHAT IS ADHESION?}

Before expatiating upon the methods of measuring adhesion, it is imperative to comprehend clearly the meaning of the term "adhesion" and the various experimental quantities measured as representations of adhesion.

The term "adhesion" is fraught with semantic difficulties and it has been defined in a variety of ways. ${ }^{11,12}$ The diversity in the definitions of adhesion stems from the fact that adhesion phenonmena are encountered in many fields resulting in specific nomenclature and terminology in specific endeavors. Qualitatively, the word adhesion

(unmodified) simply signifies the sticking together of two similar or dissimilar materials; if the materials are identical then the term "autohesion" or "homohesion" is applied, and in the case of dissimilar materials the preferred term is "heterohesion".

The difficulties arise in prescribing a quantitative definition of adhesion, and in devising some suitable experimental technique that can give numerical values of adhesion which can be compared with the valves calculated assuming various models. In the present review, adhesion. is treated in three different forms: basic adhesion; thermodynamic or reversible adhesion; and experimental or practical adhesion. Each of these manifestations of adhesion are fully explicated below.

\subsection{Basic Adhesion}

Basic adhesion is related to the nature and strength of the binding forces between two materials in contact with each other. These forces could be either primary valence type (i.e., ionic, co-valent, co-ordinate, metallic), pseudo primary valence type (i.e., hydrogen bonding), or secondary valence type (i.e., Debye, Keesom and London dispersion forces - known collectively as Van der Waals forces). But this basic definition of adhesion is not very helpful as it is not possible either to calculate the magnitude or to measure such adhesion forces in practical systems. An elegant approach based upon the molecular models was taken by Taylor and Rutzler ${ }^{13}$, but it has not been extended to a stage where this could be used to quantify adhesion in a system of interest. Relative magnitude of various forces are summarized by Good, ${ }^{14}$ as shown in Table 1.

\subsection{Thermodynamic or Reversible Adhesion}

This particular form of adhesion is defined as the reversible work done in creating a unit area of the interface between two substances. It is defined as follows:

$$
W_{A B}=\gamma_{A}+\gamma_{B}-\gamma_{A B}
$$

where $W_{A B}$ is the reversible work of adhesion, $\gamma_{A}$ the specific surface free energy of substance $A, \gamma_{B}$ the specific surface free energy of substance $B$ and $\gamma_{A B}$ is the interfacial specific free energy. This definition is simply based upon the change in free energy of the system before and after the contact is made between $A$ and $B$. The above definition is not useful in case of thin films as the various parameters are not known, so $W_{A B}$ cannot be calculated. In cases where 
TABLE I

Approximate ranges of binding energies for various types of interactions. (Reprinted from reference 14, p. 15, by courtesy of Marcel Dekker Inc.)

\begin{tabular}{|c|c|}
\hline Type of force & $\begin{array}{l}\text { Energy, } \\
\mathrm{kcal} / \mathrm{mole}\end{array}$ \\
\hline $\begin{array}{l}\text { Chemical bonds } \\
\text { Ionic } \\
\text { Covalent } \mathrm{a}^{\mathrm{a}} \\
\text { Metallic }\end{array}$ & $\begin{array}{l}140 \text { to } 250 \\
15 \text { to } 170 \\
27 \text { to } 83\end{array}$ \\
\hline $\begin{array}{l}\text { Intermolecular force } \\
\text { Hydrogen bonds } \\
\text { Dipole-dipole } \\
\text { Dispersion } \\
\text { Dipole-induced-dipole }\end{array}$ & $\begin{array}{l}\text { up to } 12 \mathrm{kcal}^{\mathrm{b}} \\
\text { up to } 5 \mathrm{kcal} \\
\text { up to } 10 \mathrm{kcal} \\
\text { up to } 500 \mathrm{cal}\end{array}$ \\
\hline $\begin{array}{l}\text { aThe "bottom cutoff" for } \\
\text { arbitrary. } \\
\text { bIn principle, there is no } \mathrm{n} \\
\text { interaction for intermolecular } \\
\text { are sometimes reported in the } \\
\text { usually minimum observed val } \\
\text { difficult to measure an energy } \\
\text { temperature } T \text {, that is very m } \\
R T=N k T \text {, because the averag } \\
\text { molecule or per degree of free } \\
k T \text {. } \\
\text { cThe smallest energy of in } \\
\text { reported is that between two } \\
\text { approximately } 0.02 \mathrm{kcal} / \mathrm{mole}\end{array}$ & $\begin{array}{l}\text { nt bonding is } \\
\text { m energy of } \\
\text { Minimum values } \\
\text { ure, but these are } \\
\text { hus it is rather } \\
\text { eraction, at any } \\
\text { aller than } \\
\text { nal energy per } \\
\text { of the order of } \\
\text { on that has been } \\
\text { atoms, }\end{array}$ \\
\hline
\end{tabular}

both $A$ and $B$ are liquids or one is solid and the other liquid, the above expression is very commonly used in one form or another to quantify the work of adhesion. ${ }^{15,16}$

\subsection{Experimental or Practical Adhesion}

More common terms for this are "bond strength" or "adhesion strength". Experimentally, adhesion can be measured in two ways: (a) in terms of the forces, defining the force of adhesion as the maximum force per unit area exerted when two materials are separated, and (b) alternatively, in terms of work or energy, defining the work of adhesion as the work done in separating or detaching two materials from one another. Forces of adhesion and work of adhesion can be related only if assumptions are made about the changes in force with distance of separation so that an integration can be performed. In other words, $W$, the work of adhesion is

$$
W=\int f(x) \mathrm{d} x
$$

If the break occurs at the interface, then it is termed adhesive failure, and if it occurs between $A$ or $B$ then it is cohesive failure. Where no definable interface exists due to interdiffusion, the measured values will represent the weakest plane in the system. It is, therefore, particularly important to locate the position of separation. In cases where there is no clear cut adhesive failure, the terms "bond strength" or "adhesion strength" should not be used but, unfortunately, there does not exist a proper term to represent nonadhesive failure; in the field of adhesives, the term "joint strength" is used to represent joint failure irrespective of the site of failure.

Assuming there is a true adhesive failure, the most important question is: What is the relationship between the bond strength and basic adhesion? This can be described by the expression,

$$
\begin{array}{r}
\text { Bond Strength }=f \text { (basic adhesion, other } \\
\text { extraneous factors) }
\end{array}
$$

These extraneous factors depend upon internal stresses and the technique used for measuring bond strength. For a given system, the bond strength values differ when measured by different techniques; furthermore, some of the techniques are operatordependent, thus compounding the problem further.

After this brief orientation, it is important to point out that the experimental values of adhesion may not have direct relevance to the basic adhesion as defined earlier. For example, if the adhesion of a polymeric film to metal is measured as the work required to detach it, then the experimental work of adhesion includes the "basic adhesion" plus the work spent in other processes, such as the inelastic deformation of the polymer. In other words, the "basic adhesion" can only be estimated from experimental adhesion provided due allowance has been made for other processes.

\section{METHODS OF ADHESION MEASUREMENT}

Before embarking on the techniques per se, two points should be made clear:

a) The practical adhesion may not be a direct measure of the basic adhesion as defined above.

b) The values of experimental adhesion obtained by different methods may not be directly comparable.

The methods of measurement of adhesion of thin films can be categorized in a number of ways:

1) Qualitative and quantitative methods.

2) Destructive and non-destructive methods.

3) Mechanical and non-mechanical methods. 
4) Fully developed, partly developed and the methods in inchoate stage.

5) Practical methods and the methods of academic interest.

6) Routine and non-routine methods.

However, in this review, the methods have been classified into three categories: (a) nucleation methods, (b) mechanical methods, and (c) miscellaneous techniques. Mechanical methods are further divided depending upon the mode of application of forces to detach the film from the substrate. Miscellaneous methods comprise the following: Thermal method, $\mathrm{X}$-ray technique, ESR, capacitance method, cathodic treatment, and pulsed laser or electron-beam technique.

\subsection{Nucleation Methods}

These methods depend upon the observation of the kinetics of formation of thin films and these can also be labelled as non-destructive methods.

Campbell in a recent review has given a detailed exposition of these methods and this obviates a comprehensive account here; only a capsule description is presented below.

In general parlance, adhesion is thought of as a mechanical property of the film. However, on an atomic scale, the removal of the film consists of breaking the bonds between the individual atoms of the film and the substrate so that macroscopic adhesion can be considered as the summation of the individual atomic forces. In principle, therefore, it should be possible to relate the adsorption energy $\dagger$ of a single atom on the substrate, $E_{a}$, to the total adhesion of the film.

It is not difficult to see from above that the adhesion determined by nucleation methods corresponds to the basic definition of adhesion as discussed earlier. Here, only the adsorption forces are considered, so the summation of individual adsorption energy of adatoms should be free from other processes which beset the mechanical methods (Sections 4.2, 4.3). It might be in order to mention that nucleation methods are based upon the measurement of (a) nucleation rate (b) island density (c) critical condensation and (d) residence time of the depositing atoms comprising the film.

Superficially, the nucleation methods seem simple and very useful in determining quantitatively

†The adsorption energy of an adatom or single atom adsorbed on a substrate is the work required to reversibly remove the atom to infinity. the adhesion of thin films but a deeper look will reveal that these methods are fairly complicated and are of limited applicability. It is necessary to have an access to an electron microscope in order to count island densities and this in turn means that it must be possible to remove the islands from the substrates without moving them relative to one another. Even if this can be done, it may not always be possible to make enough observations to separate the cohesion energy term, $E_{b}$, from the adsorption term $E_{a}$. There are not many instances in the literature where the adhesion values determined by nucleation methods have been compared with the values obtained using mechanical techniques. This arises partly from the difficulty of making meaningful quantitative measurements by mechanical methods coupled with the limited applicability of nucleation methods. Benjamin and Weaver ${ }^{17}$ calculated the adhesion energies of films of aluminum, silver and cadmium on glass substrates, and also of aluminum and silver on single crystal cleavage surfaces of sodium chloride and potassium chloride. They concluded that the adhesion energy is due to physical adsorption and can be explained in terms of Van der Waals forces alone. More recently, Chapman ${ }^{12}$ has compared the mechanical stripping measurements with nucleation results for gold on glass. He found that with the lowest stripping speeds (the value of adhesion depends upon the speed of stripping) used $(50 \mathrm{~nm} / \mathrm{sec})$, the average adhesion energy was double that obtained by nucleation methods, but he mentions that it is necessary to work at even lower stripping speeds to obtain better agreement.

A few comments regarding nucleation methods are in order: (a) These are not the tests for measuring adhesion; the information from this type of work has led to a better understanding of thin film formation and structures (b) The techniques are not applicable to completed films, (c) Unlike mechanical tests, nucleation studies yield the adsorption energy of a single adatom, and the validity of using such adsorption energy to calculate adhesion energy per unit area is questionable on the grounds that the bond energy in a continuous film will not in general be the same as that for a single atom.

\subsection{Mechanical Methods}

All mechanical methods use some means of removing the film from the substrate. These methods can be broadly classified into two categories depending upon the mode of detachment of the film: (a) methods involving detachment normal to the interface, and 
(b) methods involving the lateral detachment of the film from the interface.

\subsubsection{Methods involving detachment normal to the interface}

A force of increasing magnitude is applied to the film-substrate interface until the interface is disrupted. Either the maximum force applied is measured, or some other criterion such as area of detachment is used to designate adhesion. In these methods, an attempt is made to detach the film in a direction normal to the interface, so that the whole area of the film is detached simultaneously when the interface is broken. If the whole area is not detached simultaneously, then the analysis of the forces is more complex. The following methods are considered under this heading.

\subsubsection{Direct pull-off (DPO) method The} basic principle of the method is to attach some kind of pulling device (such as brass pins) to the back of the film by means of soldering or some adhesives and then pull the film in the perpendicular direction using a tensile tester machine (for example, Instron). Belser and Hicklin ${ }^{19}$ measured the adhesion of evaporated and sputtered metal films on glass, quartz and glazed-tile surfaces. They soldered headed brass pins to the metal films using "Cerroseal" $\left(50-50\right.$ tin-indium, m.p. $\left.118^{\circ} \mathrm{C}\right)$ or tin-lead solder and the force to pull the film, covered by the pin head, perpendicularly from the substrate surface was measured by a spring balance and winch system. The area of the pinhead was about $0.05 \mathrm{~cm}$. Similarly, Belser ${ }^{20}$ cemented the ends of $0.952 \mathrm{~cm}$ diameter aluminum cylinders with $0.3175 \mathrm{~cm}$ diameter axial holes to films and pulled them from the substrates. Frederick and Ludema ${ }^{21}$ measured the adhesion of vapor deposited aluminum films ( $25 \mathrm{~nm}$ thick) on fresh soda-glass by direct tensile method. After deposition of the film, a clean gold sphere of $0.3 \mathrm{~cm}$ diameter was pressed against the aluminum at room temperature and then pulled to separate it from glass. Beno $^{22}$ has devised a tensile test similar to that of Belser ${ }^{20}$ using solid cylinders. Chiang and Ing ${ }^{23}$ measured the adhesion of evaporated amorphous selenium films on aluminum coated with oxide layer. They cemented brass blocks to the film and substrate sides using epoxy adhesive and then pulled the assembly apart in a commercial tensile tester. Collins et al. ${ }^{24}$ measured the adhesion of evaporated aluminum films ( 40 to $50 \mathrm{~nm}$ ) on glass. Contact to the film was made by bonding a metal disc to the film using cold-setting araldite. The force to remove the film from the glass was applied either through a spring balance or a Hounsfield Extensometer. Recently Kuwahara et al., ${ }^{25}$ measured the adhesion of evaporated aluminum films on glass plates by directly pulling off the film from the substrate. Hordon and Wright ${ }^{26}$ have described a vacuum apparatus to measure interfacial adhesion based on the rupture of the interface by applying tensile force.

The direct pull-off method suffers from the following difficulties: (a) simple tensile tests are difficult to perform, and most of the time these involve a complex mixture of tensile and shear forces, which renders the interpretation of the results more difficult, (b) alignment must be perfect to insure uniform loading across the interface, (c) such tests are limited by the strengths of available adhesives or solders, (d) there is always a possibility of (i) adhesive or solvent penetrating and affecting the film-substrate interface (ii) stresses produced during setting of cement or adhesive (iii) non-uniform stress distributions or stress concentrations over the contact area during the pulling process. All of these factors affect the final adhesion strength measured.

More recently, some of the alignment problems have been overcome by Jacobsson and Kruse ${ }^{27}$ by cementing identical cylinders to the film and to the corresponding uncoated area on the reverse side of the substrate, followed by application of a tensile force normal to the film along the collinear axis of the cylinders, as shown schematically in Figure 1. Even with this arrangement, some misalignment could occur and they have accounted for the effect of this and the effect of variation of adhesive thickness. Results are presented for films of zinc sulfide, cryolite, and silver deposited on BK7 glass substrates. The forces of adhesion on ion-bombarded substrates in these cases were found to be $4.3 \times 10^{7}$, $5.4 \times 10^{7}$, and $2.3 \times 10^{7} \mathrm{~Pa}$ respectively.

Apropos, Cramer et al, ${ }^{28}$ have described a similar arrangement for adhesion measurement of electodeposits and the effect of the misalignment of rods or cylinders was derived from the basic formulas for the flexural behavior of beams.

\subsubsection{Moment or topple method A slight} variation of the direct pull-off method has been investigated in which instead of applying the force vertically to the interface, it is applied in a horizontal direction to a rod glued to the film, and the moment of the force required to break the film from the substrate is a measure of adhesion. Butler ${ }^{29}$ has described a simple film adhesion comparator 


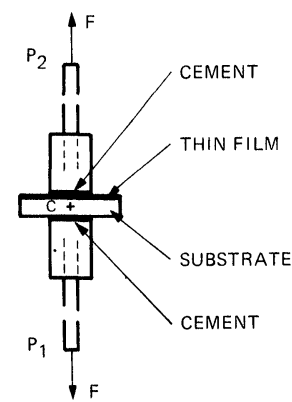

FIGURE 1 Diagram for adhesion test by application of a normal pulling force. The force $F$ is applied at $P_{1}$ and $P_{2}$ with the force aligned through the center $C$ of the substrate. Identical steel cylinders are cemented on the coated top side and uncoated lower side of the substrate. (From reference 27)

based upon this principle. Butler points out that this method has advantages over the direct pull-off method because (a) this arrangement offers less substrate distortion since there would be no resultant overall force normal to the plane of the substrate and (b) this apparatus would not require such critical alignment as in the case of normal pull.

In this arrangement, as shown in Figure 2, one end of the rod is cut to form two short legs and the results are calculated assuming pure tension under one leg and compression below the other leg. Butler observed that tensile stresses in excess of $4 \times 10^{7} \mathrm{~Pa}$ could be obtained for copper films deposited on glass substrate. The adhesive used for glueing was Eastman 910. Subsequently, the technique has been used by Butler et $a l,{ }^{30}$ and Stoddart et al. $^{31}$ Wieckowski $^{32}$ has analysed the methods for checking adhesion of conductive thin films and has concluded that the method of detachment using a side force seems to be the best. The objections regarding the use of adhesives or solders also apply to this modification as discussed for the direct pull-off method.

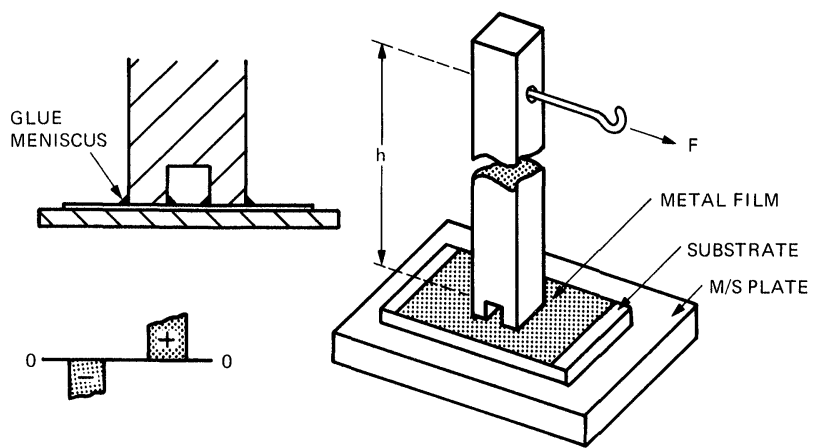

FIGURE 2 Diagram showing arrangement for the moment or topple method. (From reference 29, Copyright: Institute of Physics, England)

\subsubsection{Ultracentrifugal method The direct pull-} off method suffers from the drawback that some sort of adhesive or solder is required to attach some device to pull the film, which is sometimes highly undesirable. In the ultracentrifugal technique no adhesive or solder is used, and adhesion is determined by measuring the force necessary to detach a film normal to the surface. As the name suggests, the specimen is in the form of a rotor which is spun at extremely high speeds to provide the requisite centrifugal force as shown schematically in Figure 3. At a critical speed of rotation, the coating can no longer withstand the centrifugal stress and is detached. Hallworth ${ }^{33}$ appears to have been the pioneer of this technique which he described as "whirl test". But the real progress in the design of the equipment has been through the efforts of Beams et $a l^{34}$ who suspended the rotor in a vacuum in a

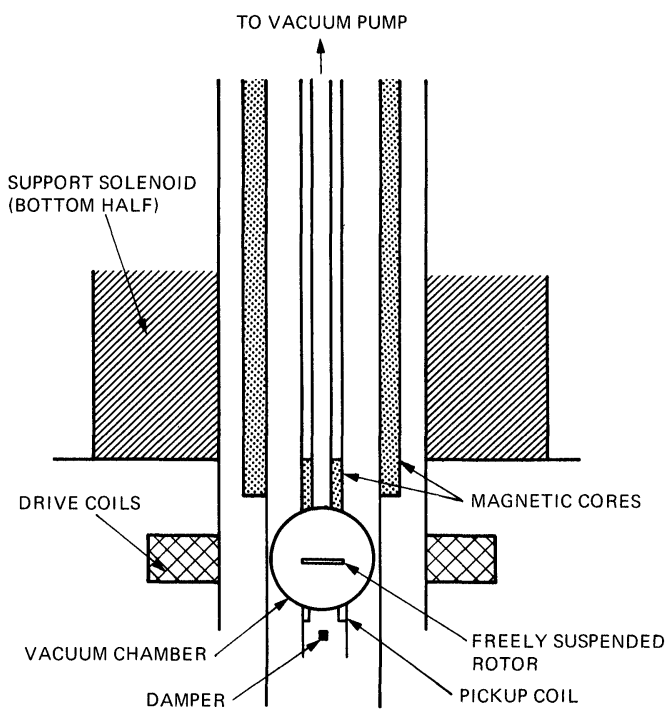

FIGURE 3 Diagram of ultracentrifugal arrangement for measuring adhesion. (From Handbook of Thin Film Technology, L. I. Maissel and R. Glang, Editors). Copyright (1970) McGraw-Hill Book Company. Used with permission of McGraw-Hill Book Company.

magnetic field and applied a rotating magnetic field to spin the rotor. More recently, Dancy ${ }^{35}$ has designed a modern version of this system with angular speeds in excess of $80,000 \mathrm{rps}$. In the past, the main concern has been that the rotor should be ferromagnetic and this limited the study of coatings to only a few substrates. But with the latest design of Dancy, coatings on nonmagnetic substrates may also be investigated with the magnetic support system. The 
nonmagnetic specimen must be rendered magnetic and this can be accomplished by the inclusion of a ferromagnetic rod that is aligned along the axis of rotation, or by the addition of a ferromagnetic disc which is cemented to one end of a test rotor. The possible stress distribution within the rotor must now be calculated considering the influence of this added body. In all cases, the maximum speed $\dagger$ of rotation is governed by the mechanical properties of the rotor (or the weakest material in a composite rotor) and for any given material can be increased only by reducing the overall diameter of the rotor. For example, with mild steel the speed would be limited to $30,000 \mathrm{rps}$ for $0.470 \mathrm{~cm}$ diameter rotor, increasing to $45,000 \mathrm{rps}$ for $0.3125 \mathrm{~cm}$ diameter. Table II summarizes the bursting speeds and other parameters for spherical steel rotors of different diameters.

TABLE II

Bursting-speeds of spherical steel rotors (from reference 34a)

\begin{tabular}{llll}
\hline $\begin{array}{l}\text { Rotor } \\
\text { Diam. } \\
(\mathrm{mm})\end{array}$ & $\begin{array}{l}\text { Rotor } \\
\text { speed } \\
\left(10^{3}\right. \\
\mathrm{rev} / \mathrm{min})\end{array}$ & $\begin{array}{l}\text { Peripheral } \\
\text { speed } \\
\left(10^{3}\right. \\
\mathrm{cm} / \mathrm{sec})\end{array}$ & $\begin{array}{l}\text { Centrifugal } \\
\text { acceleration } \\
\left(10^{6} \mathrm{~g}\right)\end{array}$ \\
\hline 3.97 & 4,420 & 96 & 47.1 \\
2.38 & 7,410 & 92.5 & 72 \\
1.59 & 12,660 & 105 & 143 \\
0.795 & 23,160 & 96.5 & 240 \\
0.521 & 37,980 & 104 & 428 \\
0.398 & 48,000 & 100 & 515 \\
\hline
\end{tabular}

In the ultracentrifugal system, the forces on the coating are given by:

$$
T=\frac{A r}{t}=\frac{4 \pi^{2} n^{2} r^{2} d}{g}\left(1+\frac{t}{r}+\frac{t^{2}}{3 r^{2}}\right)
$$

where $T$ is the hoop stress

$A$ is the adhesion in $\mathrm{g} / \mathrm{cm}^{2}$

$r$ the radius of the rotor in $\mathrm{cm}$

$n$ is the number of revolutions per second

$d$ density of the coating in $\mathrm{g} / \mathrm{cm}^{3}$

$t$ thickness of the coating in $\mathrm{cm}$

and $g$ is the acceleration due to gravity

$$
\left(981 \mathrm{~cm} / \mathrm{sec}^{2}\right) \text {. }
$$

The hoop stress, $T$, can be eliminated by making slits in the coating parallel to the axis of rotation or

$\dagger$ According to Guinness Book of World Records ${ }^{36}$ the highest man-made rotatory speed ever achieved is $1,500,000 \mathrm{rps}$ on a steel rotor with a diameter of about $0.025 \mathrm{~cm}$, installed in 1961 in Professor Beams' laboratory at the University of Virginia, Charlottesville. in case of hard coatings like chromium, it is automatically eliminated as shown by Dancy and Zavarella. ${ }^{37}$ Under the conditions of $T=0$, the above equation reduces to: $A=$ $4 \pi^{2} n^{2} r d t / g$. From this equation, it is clear that the rotor size will be dictated by the degree of adhesion to be measured. For example, for $n=30,000 \mathrm{rps}$, the maximum measurable adhesion using a $0.470 \mathrm{~cm}$ diameter rotor with $0.0125 \mathrm{~cm}$ coating having a density of $8.3 \mathrm{~g} / \mathrm{cm}^{3}$ would be $9.14 \times 10^{5} \mathrm{~g} / \mathrm{cm}^{2}$ or $9.1 \times 10^{7} \mathrm{~Pa}$. If the adhesion strength exceeds $9.1 \times 10^{7} \mathrm{~Pa}$ then the above combination of various dimensions is not satisfactory unless the speed is increased. If the speed and the rotor radius have to be maintained, then the increse in either the thickness or the density of coating will increase the value of A.

Beams et $\mathrm{al}^{34}$ obtained acceleration of the rotor of $10^{9}$ times normal gravity, acceleration being limited by the bursting strength of the rotor. However, their results deal only with the poorly adherent films and the surface was deliberately contaminated before deposition of silver films to reduce adhesion. Beams ${ }^{34}$ reports the work of Dancy and Kuhlthau in which they studied the adhesion of electrodeposited chromium films $(0.0254 \mathrm{~cm}$ in thickness) on cylindrical steel rotors from 0.3175 to $0.9525 \mathrm{~cm}$ in diameter and obtained an effective adhesion of $1.13 \times 10^{8} \mathrm{~Pa}$. If the same method were applied to an evaporated chromium film of about $50 \mathrm{~nm}$ thickness, and assuming the same density of the film, then a centrifugal acceleration of $3 \times 10^{10}$ times normal gravity would be required, which is considerably more than the value of $10^{9} \mathrm{~g}$ obtained by Beams et al.

Other workers have also used the ultracentrifugal technique to measure the adhesion of electrodeposited copper

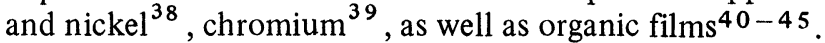

In summary, this technique is quite versatile if the rotor materials are selected properly, then a variety of coatings can be studied. Particularly, with the advent of the solid-state ultracentrifuge, the technique offers increased promise ${ }^{35}$. The following comments are in order: (i) no adhesive or solder is required, (ii) the choice of the rotor material is important as the extent of adhesion values which can be measured will be dictated by the rotor material, (iii) in polymeric coatings, the viscoelastic properties play an important role, (Iv) in case of very thin deposits, it may be difficult to obtain the requisite centrifugal force as the total force is the product of mass and acceleration, and if mass is small, acceleration must be increased and this is limited by the rotor material, (v) no systematic study of the effect of thickness, or the rate of acceleration has been 
conducted, and (vi) if the temperature of the rotor rises above the glass transition temperature of the polymeric film, then the situation is quite complicated. In addition, Huntsberger ${ }^{4}$ observed that the values of adhesion obtained by this technique are lower than those obtained by other methods, and this could be explained if the film exhibited creep leading to a peeling phenomenon, where the load to start detaching the film would be far less than the normal force to throw it off. Reference ${ }^{44}$ should be consulted for criticisms of this technique. Before leaving the discussion of this technique, it should be emphasized that systematic work needs to be done on the adhesion measurement of thin films, polymeric or metallic, to various substrates using this technique.

\subsubsection{Ultrasonic method Before discussing this} method, it may be proper to point out clearly that the ultrasonic method has been applied to study the adhesion of relatively thicker paint films; the references where thin films have been studied are extremely scanty. An early original paper describing this method in the study of adhesion is that of Moses and Witt ${ }^{46}$. In this method, the normal force is supplied by the inertia of the coating subjected to rapid reversals of motion at ultrasonic frequencies. They studied the adhesion of polystyrene and vinyl resin films on metal cylinders. The method and apparatus utilize an electrodynamic system for producing longitudinal ultrasonic vibrations in a metal cylinder. A film attached to the free end of the vibrating cylinder separates from the metal when the force due to the acceleration exceeds the adhesion force at the interface. The accelerating force is determined by the frequency and amplitude of vibrations and by the mass and area of the film. The amplitude of vibrations of the rod or cylinder is calculated from the input voltage. The maximum acceleration is given by $4 \pi^{2} f_{0}^{2} a, f_{0}$ being the fundamental frequency of vibration given by $(l / 2) \sqrt{ } E / \rho, E$ being Young's modulus, $l$ the rod length and $\rho$ the density. By knowing the dimensions and density of the film one can determine the force at each reversal. It was calculated that at a frequency of $20 \mathrm{kHz}$, the maximum acceleration would be of the order of $2 \times 10^{3}$, and at $50 \mathrm{kHz}, 5 \times 10^{5}$ times normal gravity. The mechanical restrictions on the system limited the choice of cylinder material to magnesium or aluminum alloys, and to increase the versatility of the method screw caps were used at the ends of the cylinder. These screw caps could be other metals.
Moses $^{4} 7$ measured the adhesion of polystyrene films deposited from toluene solution onto dural cylinder at a frequency of $23.6 \mathrm{kHz}$, and the adhesion was of the order of $4.14 \times 10^{5} \mathrm{~Pa}$. The thickness of the film was not clearly mentioned.

Although the thickness of the film was not mentioned, it is very clear that he used polymeric films thicker than $1 \mu \mathrm{m}$, thereby he could use a relatively low frequency to separate the thicker film from aluminum metal. As pointed out earlier an acceleration of the order of $5 \times 10^{5}$ times normal gravity is obtained at a frequency of $50 \mathrm{kHz}$; higher accelerations may be obtained by working at higher frequencies which means using piezo-electric transducers and for fundamental operations of a quartz, vibrator the limiting frequency is usually of the order of $12 \mathrm{MHz}$. Using a frequency of $10 \mathrm{MHz}$ can raise the acceleration to $10^{9}$ times normal gravity, which is of the same order as that obtained by Beams ${ }^{34}$ in the ultracentrifugal technique. More recently Faure et $\mathrm{al}^{48}{ }^{48}$ fixed the film support to the ends of an amplifier of mechanical vibrations, the vibration being induced by a piezoelectric transducer. The films used were granular and fissured silver films. Furthermore, assuming that the frequency of the mechanical vibration is much smaller than the natural frequency of the silver grains, the order of magnitude of the adhesion between the grains and the support has been estimated. In addition, they have pointed out that the adhesion of continuous films can also be measured by this method. On the basis of the above discussion, it is apparent that more work using thin films is necessary before its usefulness can be established. The effective force can be increased by raising the mass of the film (essentially increasing the thickness), but it is a well known fact that the adhesion of vacuum deposited films is affected by the stresses in thick films and cases are known where very thick layers peel spontaneously. So measurements on thick films may give misleading results when the information is extrapolated to thin films. However, this is a potential method which can be evolved into a quantitatve technique for measuring adhesion.

\subsubsection{Methods based upon the application of lateral stresses for detachment}

The primary purpose here is to apply lateral stresses so as to cause the detachment of the film from the substrate. The methods most widely used by paint technologists to apply such lateral stresses are bend, cupping, or impact tests, or by attacking the paint film by plough or knife tests, or in some instances both 
together as in most scratch test variants. Many of these tests may lead to cohesive cracking of the film but careful inspection often reveals that the coarseness of crack pattern is directly related to inadequacy of adhesion. Moreover, a film might appear merely to have cracked but will often peel spontaneously from the cracks within a short time of testing, indicating that adhesion failure had in fact begun over a substantial area. Before discussing methods under this heading and which are applicable to thin films, it might be stressed that some of the techniques might be very useful in the area of paint films but might not be valid when studying adhesion of thin films. Only those techniques which have shown promise for the adhesion of thin films are discussed below.

4.2.2.1 Scotch tape method This is a relatively old technique for testing adhesion and is usually attributed to Strong ${ }^{49}$. A pressure sensitive tape is pressed onto the film and then rapidly stripped. Three possibilities arise: (a) the film is completely removed from the substrate (b) film is not at all removed, and (c) the film is partly removed or removed in patches. So it is apparent that this test is highly qualitative and can be used to screen cases involving very poor adhesion from those where adhesion is appreciable. Strong ${ }^{50}$ himself used this test to determine the adhesion of evaporated aluminum films on glass and observed a pronounced effect of cleaning of the glass on the degree of adhesion Williams and Backus ${ }^{51}$ employed this test to study the effects of variables on the adhesion of evaporated thin metallic films on glass. Thin films of approximately $2 \mathrm{~nm}$ thickness were deposited on clean microscopic-slide glass and their relative adherence tested by their resistance to removal by means of stripping with a film of collodion. This way they could categorize the metal films into various classes depending upon their ease of removal. Recently Haq, Behrndt and Kobin ${ }^{52}$ have used this test to study the adhesion between glass or oxidized silicon substrates and evaporated gold films in combination with an adherent intermediate layer of $\mathrm{Ta}, \mathrm{Si}, \mathrm{Ge}$, or $\mathrm{Cr}$. This way they were able to study the changes in adhesion as a function of relative thickness of $\mathrm{Au}$ and underlayer films as well as of time, environment and treatment after deposition. As this test is only qualitative, they could distinguish complete lifting, partial lifting, and no lifting of the films as shown in Figure 4. It is interesting to notice that they found that the adhesion of $\mathrm{Au}$ films to glass substrate was a function of the thickness of the film; while very thin films $(<10 \mathrm{~nm})$ adhered strongly, complete lifting was observed for thicknesses above about $17 \mathrm{~nm}$, with partial lifting for the intermediate thickness. Mattox and $\mathrm{McDonald}{ }^{53}$ used this method to study the adhesion of sputtered cadmium films on iron and they could investigate qualitatively the effects of the techniques of depositing films on the substrate.

Although this test is highly qualitative, it offers certain advantages: (a) it is a very inexpensive and quick test, so it can be utilized for screening cases of

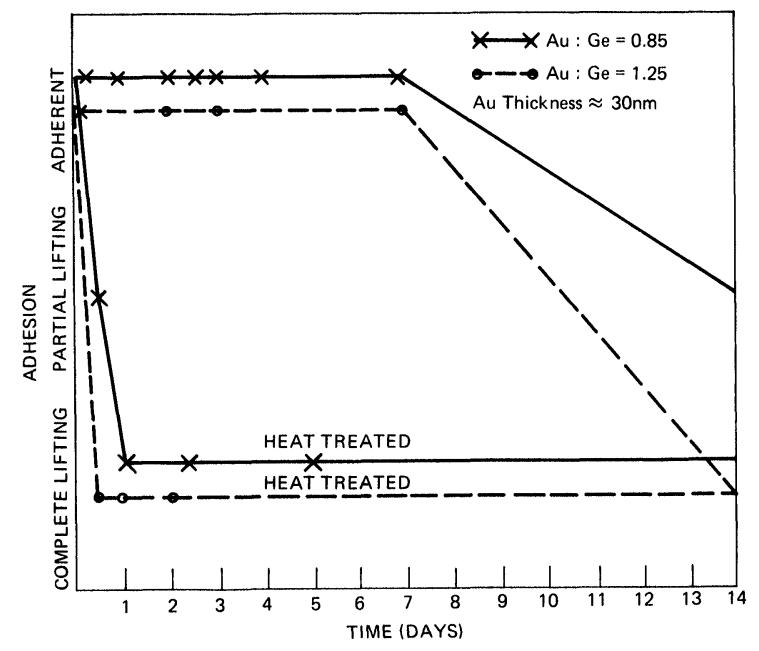

FIGURE 4 Change of adhesion with time for different $\mathrm{Au}-\mathrm{Ge}$ film combinations. (From reference 52).

very poor adhesion from the ones showing appreciable adhesion (b) this test can prove very valuable in an exploratory research where effect of various operating variables is studied (c) it can prove useful in studying the effects of humidity, temperature, and other factors on the adhesion between the film and the substrate. A few of its inherent weak points can be enumerated as: (a) highly qualitative so no numerical values of adhesion can be obtained and this renders it incomparable to other techniques (b) type of tape, application pressure, and the manner of stripping affect the final results and this makes it difficult to compare results obtained by different workers, (c) applicable only when the adhesion between the film and the substrate is less than that between the tape and the film; so, it cannot be used in cases where the films adhere very tenaciously to the substrate. Beno $^{22}$ reports that such tests are limited to adhesion of about $5.17 \times 10^{5} \mathrm{~Pa}$. 
4.2.2.2 Peel test The film can be peeled from the substrate in two ways: (a) by directly holding onto the film, and (b) by applying some sort of backing material to the film and then holding onto the backing. The actual peel test involves peeling a specified width of the film, as shown in Figure 5, at a specified angle, $90^{\circ}$ being the most common. In this test, it is virtually impossible to specify the area involved at any instant, so the force used in peeling thereforce has little significance. The results are expressed as energy or work done per unit area. So the results from peeling experiment are not directly comparable to the results obtained using other techniques which provide adhesion values in terms of force per unit area. Furthermore, in order to make any useful measurement, the film must be completely removed from the substrate, which limits the applicability of this technique to those interfaces which exhibit relatively poor adhesion.

Sundhal ${ }^{54}$ has studied the adhesion of $\mathrm{Ta}_{2} \mathrm{~N}-\mathrm{Ti}$ $\mathrm{Pd} \mathrm{Au}$ films on high purity $\mathrm{Al}_{2} \mathrm{O}_{3}$ substrates by $90^{\circ}$ peel tests performed on leads which were thermocompression bonded to the films. From his finding he concluded that a necessary requirement for good adhesion of these films to alumina substrates was the presence of a minimum amount of $\mathrm{Ca}$ and/or $\mathrm{Si}$ at the surface. He selected the $90^{\circ}$ peel test because this seemed to simulate the conditions in the fabrication of reliable thin film circuits. The thickness of the films was $\sim 1.5 \mu \mathrm{m}$. Bonds which failed at the interface at a force of less than $2.5 \mathrm{~kg}$ were considered symptomatic of poor adhesion.

Chapman ${ }^{18}$ has employed peeling technique in the study of adhesion of gold films on soda lime. He terms it the mechanical stripping method which is a quantitative version of the qualitative Scotch tape test. He has used both supported and unsupported films, consequently he used two different arrangements: (1) In this case a tape is attached to the back of the film. The tape is then attached via a thin trapeze to the winding string. As the stripping proceeds, the tape and the film are removed from the substrate. (2) The tape is attached only to the first part of the film and then the tape and the film are scribed out, with a razor blade as shown schematically in Figure 6. Stripping then proceeds from the tape-film combination to the unsupported film and it is on the unsupported film only that the measurements are made.

Chapman obtained energies of the order of $2000 \mathrm{erg} / \mathrm{cm}^{2}$ in the case where backing material was used; in the case of thicker gold films, which obviates the need for backing material, the measured peel

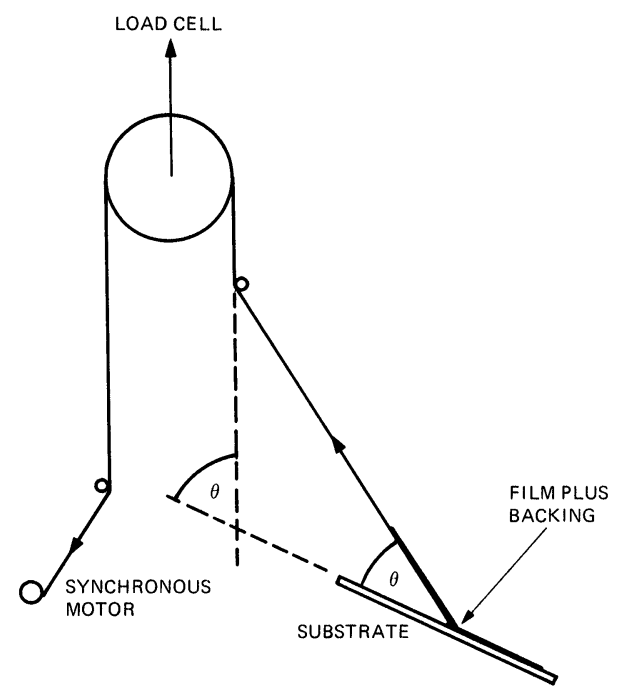

FIGURE 5 Diagram of apparatus for stripping or peeling experiments. (From Handbook of Thin Film Technology, L. I. Maissel and R. Glang, Editors. Copyright: 1970 McGraw-Hill Book Company. Used with permission of McGraw-Hill Book Company.

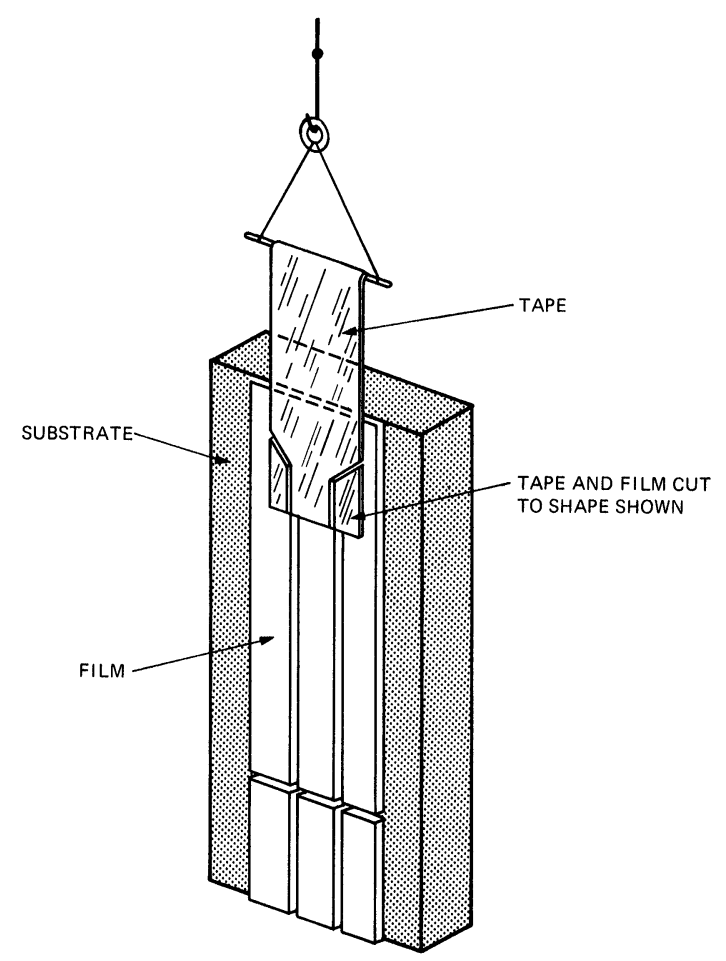

FIGURE 6. Diagram for peeling experiments on unsupported films. (From reference 18.) 
energies fell to about $500 \mathrm{erg} / \mathrm{cm}^{2}$. Moreover, the peel values depend upon the rate of peel, and the residual gas pressure. All these observations signify that the measured peel energy consists of two components: (a) true adhesion energy, i.e., the energy of adhesion due to intermolecular interactions, and (b) the energy spent in the inelastic deformation of the film material. So unless the work expended in the deformation of film material is known and accounted for, one cannot determine the energy of adhesion. In the case of polymeric films, in addition to the rate of peel, angle of peel, width of peel, the temperature of peel are also important in dictating the final measured peel energies. Chen and Flavin ${ }^{55}$ have discussed the mechanics of film peel adhesion and the effects of non-elastic behavior of the film are analysed. Poley and Whitaker ${ }^{56}$ have recently employed the dynamic peel test in understanding the effects of cleaning procedures, substrates, vacuum treatments, and glow discharge ambients on the chromium-glass adhesion.

\subsubsection{Tangential shear or lap shear method}

This technique has not been as popular as the direct pull-off method, but in certain cases lap shear test simulates better the actual application conditions of thin films, so the results using this test may be more meaningful. Very recently, $\operatorname{Lin}^{57}$ has measured the adhesion of $\mathrm{Au}, \mathrm{Cu}$, and $\mathrm{Al}$ films (of thicknesses from 0.05 to $40 \mu \mathrm{m}$ ) to glass and $\mathrm{MgO}$ single crystal substrates using this test. For films deposited mainly at a vacuum of $10^{-7}$ to $10^{-8}$ Torr, the shear stress was found to be virtually independent of the film thickness and had mean values of $3 \times 10^{5} \mathrm{~Pa}$ for $\mathrm{Au}$, $8 \times 10^{5} \mathrm{~Pa}$ for $\mathrm{Cu}$ and $1.5 \times 10^{6} \mathrm{~Pa}$ for $\mathrm{Al}$ films on glass. The measured shear stress is the tangential force per unit area required to break the bond between the film and substrate. The experimental arrangement is shown schematically in Figure 7.

A piece of glass microscope slide is bonded to the upper surface of the film which has been deposited on the desired substrate. The film and the substrate are then clamped rigidly in position and a shear force applied parallel to the film by weights attached to a thin stainless steel wire passing over low friction pulley. A normal load of 0.110 to $0.2100 \mathrm{~kg}$ is also present to counteract any pivoting tendency about the edge of the test piece. The shear stress values are calculated from the force required to break the bond between the film and the substrate divided by the area of contact of fast-set adhesive. Lin has pointed out that the most satisfactory and convenient to apply adhesive was the cyanoacrylate monomer (Eastman Kodak 910). Furthermore, he did not observe any penetration of this adhesive through the films. Lin has compiled an extensive table summarizing the shear stress values of different films and substrates measured for a variety of film deposit variables. A few comments regarding this technique are in order: (1) An adhesive is used in this test as in the direct pull-off or moment method and thus this technique suffers from the same weaknesses and

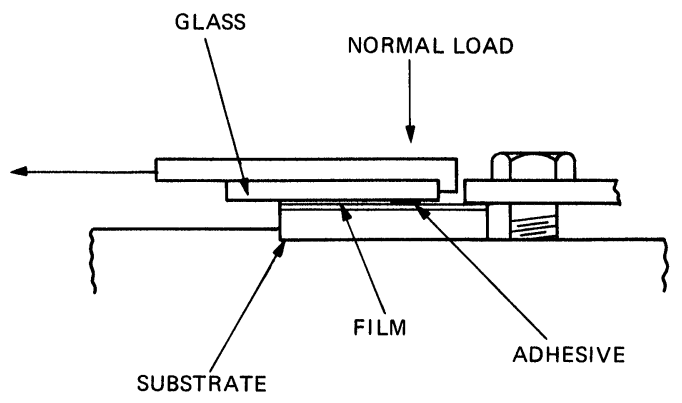

FIGURE 7 The lap shear test arrangement for measuring adhesion. The arrow shows the direction of the shear force. (From reference 57, Copyright: The Institute of Physics, England.)

criticisms as enumerated earlier in the discussion of direct pull-off method. The undesirable effects of adhesives are aggravated in the study of polymeric films and although Lin did not find any diffusion of the adhesive through the metallic films, this may not be true in polymeric films, (2) According to Lin, this simple lap shear test has these advantages: (a) it avoids severe deformation of the substrates, (b) the film is gripped over a relatively large area, thus the stress is less concentrated, and (c) it approximates to a nominally "pure shear" measurement even though stereoscan and optical microscopy observation indicated that peeling is involved after initiation of shear in some regions. (3) It is important to mention that Lin observed that the shear stress values were about 100 times smaller than those obtained in measurements where the force is applied normal to the substrate and this could be explained by showing that the films are more easily removed by a force parallel to the substrate than by a perpendicular force (the theoretically predicted ratio between the shear and tensile stresses is 1:4).

Dini et al. ${ }^{58,59}$ have described a ring shear test to measure quantitatively the adhesion of electrodeposits, the thickness of these deposits being much more than that of thin films. In this method, essentially, a cylindrical rod is coated with separate 
rings of electrodeposits of predetermined width. This rod is forced through a hardened steel die having a hole larger in diameter than the rod but less than that of the rod plus the coating. The coating is detached and the adhesion strength $\mathrm{A}$, determined by the formula, $A=W / \pi d t$, where $d$ is the diameter of the rod, $t$ is the width of the deposit, and $W$ is the force required for detaching.

Although this technique was not used in the study of adhesion of thin films, but there appears to be no fundamental objection or difficulty; so it should certainly be tried for the case of thin films. There may be some difficulty in getting dies machined to precise diameters, but it does not appear insurmountable.

\subsubsection{Scratch or stylus or scribe method In the} recent past this test has become a controversial issue and arguments have been extended both for defence and attack. Essentially, in this test, shown schematically in Figure 8 a smoothly rounded chrome steel, tungsten carbide, or diamond tip ( $\sim 0.003$ to $0.005 \mathrm{~cm}$ radius) is drawn across the film surface, and a vertical load, applied to the point, is gradually increased until the film is completely removed resulting in a clear channel. The critical load at which the clear track is formed is taken as a measure of adhesion. Heavens ${ }^{60}$ and Heavens and Collins ${ }^{61}$ were the first to use this test to study quantitatively the adhesion of thin evaporated metallic films on glass and the effect of chromium interlayers. Weaver and Hill ${ }^{62}$ studied the increase in adhesion of aluminum films to glass by the predeposition of films of chromium. They also used the load necessary to strip the film completely as a measure of adhesion.

The test remained semi-quantitative and no numerical values of adhesion could be obtained until 1960 when Benjamin and Weaver ${ }^{63}$ analysed the scratch test in detail and derived some simple equations to convert the critical load into numerical values for adhesion. A capsule description of their analysis and findings is given below. A detailed analysis showed that the action of the point always involved plastic deformation of the substrate and this deformation produces a shearing force at the film substrate interface around the rim of the indentation produced by the point, and a simple relationship between the applied load and the shearing force was developed, so that adhesion could be calculated as a shearing force.

$$
F=\frac{a P}{\sqrt{r^{2}-a^{2}}}, \quad \text { where } \quad a=\sqrt{\frac{W}{\pi P}}
$$

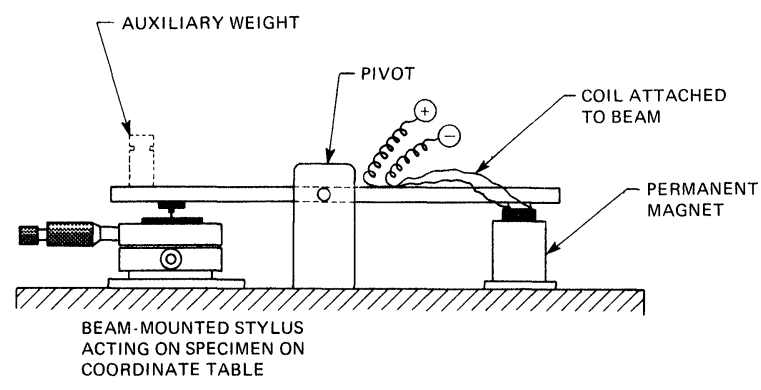

FIGURE 8 Schematic layout of scratch or stylus test. (From reference 70, Copyright: The Institute of Physics, England.)

Where $W$ is the critical load, $r$ is the radius of the tip, and $F$ is the shearing force per unit area due to the deformation of the surface, $a$ is the radius of the circle of contact, and $P$ is the indentation hardness of the substrate material.

Based upon their studies of adhesion of evaporated silver films on various substrates, and of various evaporated metal films on glass, Benjamin and Weaver found that (a) in each case, the measured load became constant for film thicknesses exceeding a certain value; this value was close to $80 \mathrm{~nm}$. For thinner films a slightly smaller load was required and they surmised that this could be attributable to film structure and it was no innate weakness of the method (b) the load did not depend directly upon the mechanical properties - hardness, elasticity or tensile strength - of the film as the load did not vary with the thickness of the film. (c) the load depended upon the nature of both the film and the substrate, without being directly attributable to the mechanical properties of either. From these observations they concluded that the load is determined essentially by the properties of the interface.

The scratch test has since been used for many years to show ageing effects in adhesion, ${ }^{6-67}$ and to investigate alloying effects due to diffusion in two layer metal films. ${ }^{68}$

Weaver and Parkinson ${ }^{68}$ offered the most convincing evidence that the critical load was determined primarily by the adhesion between the film and the substrate from their experiments with two layer metal film on glass. Gold was deposited on glass which was overlaid with aluminum. As gold has a relatively poor adhesion to glass, so the measurements started at low value. Aluminum has a much higher adhesion to glass and they observed an abrupt increase in adhesion at exactly the stage where aluminum, in the form of intermetallic with gold, 


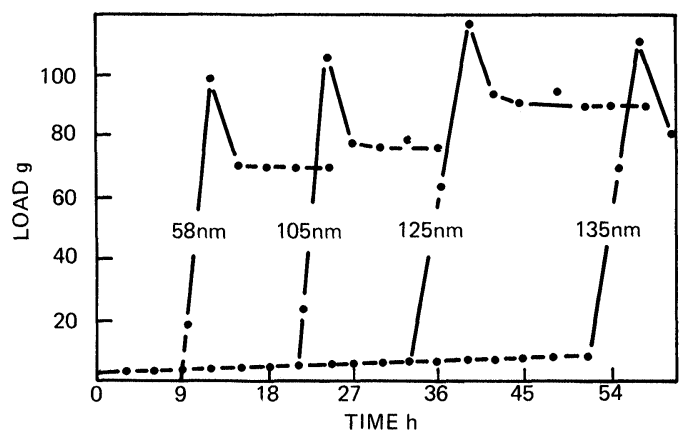

FIGURE 9 Adhesion changes during annealing of $\mathrm{Au}-\mathrm{Al}$ thin-film diffusion couples with gold underlayers. Different thicknesses of gold underlayers are shown in the diagram. (From reference 68.)

appears at the metal-glass interface, as shown in Figure 9. Furthermore, an exact parabolic relationship between the gold thickness and the time as measured up to the break in the adhesion curve was found, which is in accordance with the diffusion theory. The scratch test enjoyed a substantial degree of popularity but recently it has been criticized by various groups. ${ }^{30,69}$

Recently Butler, Stoddart and Stuart ${ }^{30}$ employed the scratch test to study the adhesion of vacuum deposited $\mathrm{In}, \mathrm{Sn}, \mathrm{Pb}, \mathrm{Au}, \mathrm{Cu}, \mathrm{Al}, \mathrm{Ni}, \mathrm{Cr}$ and $\mathrm{Mo}$ (of various thicknesses up to $3.2 \mu \mathrm{m}$ ) on glass using diamond and steel styli with tip radii of approximately $25 \mu \mathrm{m}$ and loadings of up to $0.230 \mathrm{~kg}$. Using scanning electron and optical interference microscopy they showed that the process of scratch formation was very complex and varied with the film material, indicating that it was not possible to deduce absolute values of adhesion using a simple general theoretical model.

Some of their comments are summarized below:

1) Their work has shown the unreliability of simple optical methods of detecting re-adherence caused by the sliding stylus. A film can become detached before the formation of a cleared track and conversely a film may be thinned to optical translucency without being removed.

2) The form of the track depends on the elastic and plastic deformation of the film and substrate, i.e., it depends primarily on their hardnesses.

3) There is no preferential failure (i.e., yielding of a permanent nature) at the film substrate interface: factors such as the size and surface finish of the stylus as well as the thickness of the film can determine whether failure occurs first in the film or in the substrate or at the interface.

4) Film detachment often occurs at lighter loads than required for track clearance which appears to depend on film tearing, film pile-up in front of the stylus, dust, imperfections, etc.

Figure 10 is an electron micrograph of the scratch produced which shows film becoming detached and forming a small hillock or bubble ahead of the stylus and some detachment and raising of the film on either side of the actual track. ${ }^{70}$ Very recently, Weaver ${ }^{10}$ has analysed the behavior depicted in Figure 10, and his theoretical analysis, apparently, offers explanation for all the observable details in the micrograph. Moreover, it modifies and expands the details of how the film is removed, but the initial state is still dependent upon the shearing force under the stylus. Also Weaver has explained why styli of certain materials give consistent values of critical load, while others are not too useful.

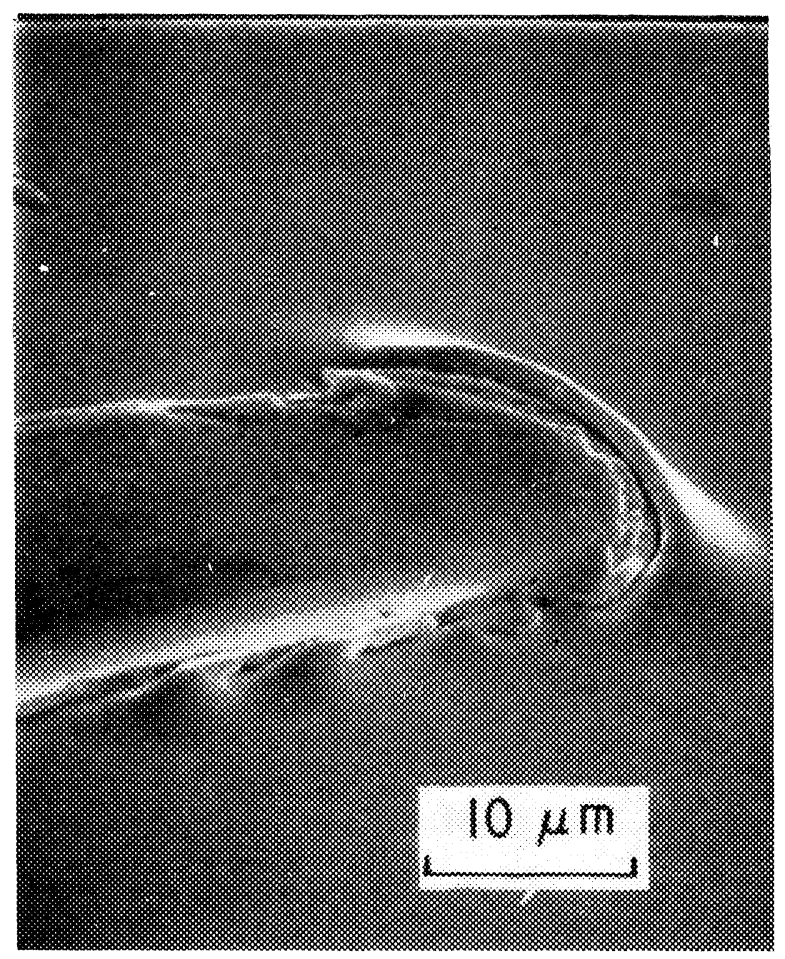

FIGURE 10. Track due to a moving stylus which has caused film (copper) detachment ahead of the stylus. The edges of the track contain extruded, raised and folded film. Film thickness $0.24 \mu \mathrm{m}$; stylus load $40 \mathrm{~g}$; angle of view $21^{\circ}$ to film plane. (From reference 70, Copyright: The Institute of Physics, England.) 
Scratch test has been employed by many workers in studying the adhesion of an assortment of films ${ }^{53,71-75}$ It is important to point out that Chopra ${ }^{69}$ found that the critical load (in the case of polycrystalline $\mathrm{Au}$ films deposited on glass) increased nearly linearly with film thickness above $200 \mathrm{~nm}$, which suggests that the critcial load is determined both by the adhesion at the interface and the mechanical strength of the film. Hamersky ${ }^{72}$, in his studies of adhesion of aluminum films deposited on glass slides, concluded that the the accuracy of the scratch test result is dependent on the point radius and only indirectly on its hardness. The method gives results which are reproducible using a point radius larger than $0.2 \mathrm{~mm}$. Berendsohn ${ }^{75}$ studied adhesion of a variety of films on different substrates and Table III summarizes selected results from his work.

So far the discussion of the scratch test has centered around the measurement of critical load, but Oroshnik and Croll, ${ }^{73}$ during their detailed studies of the scratch test, found that complete removal of a film (e.g. aluminum) by a stylus was an infrequent event. At stylus loadings below (and often above) the so-called "critical load" there was only partial removal of the film, but not necessarily in relative proportion to the loading. This led them to develop the concept of "Threshold Adhesion Failure" as an operational criterion for adhesion measurements. It is defined as follows:

Threshold Adhesion Failure occurs if, within the boundaries of a scratch and over its $1 \mathrm{~cm}$ path, removal of the film from its substrate can be detected by transmitted light with a microscope (40x magnification) at even one spot no matter how small.

Measurements embracing this new criterion are made using the "up-and-down" or "staircase" method. The stylus is incrementally loaded for successive scratches in the load range where threshold failure is expected. Measurements were made largely on $0.5 \mu \mathrm{m}$ thick vacuum evaporated aluminum films on fused quartz substrates using diamond styli with nominal curvature radii of $44 \mu \mathrm{m}$. Some of their findings are: (1) The scratch test can discriminate between stylus loads 0.1 g apart, the resolution of the apparatus; (2) Mean Threshold Adhesion Failure loads are relative measurements; (3) No tw o styli of any one material (diamond or tungsten carbide) of the same nominal tip radius of curvature yield the same Threshold Adhesion Failure load values; (4) Any one stylus exhibits its own individual scribing and testing characteristics; (5) Each material (e.g. gold as compared with aluminum) shows a different scratch test behavior, thereby requiring suitably modified measurement techniques. The findings of Oroshnik and Croll certainly necessitate further probing into the complexities and detailed mechanics of the scratch test.

Although there may be some criticism apropos of conversion of critical loads into quantitative adhesion values, yet the technique can be profitably used to (i) Follow the effect of deposition parameters and other experimental variables, and thereby determine the optimum adhesion parameters. (ii) Detect coatings of marginal adhesion. (iii) Test an area too small for other tests. (iv) Study the effects of aging, weathering, point-to-point variation, i.e., to check the uniformity of substrate-film adhesion. A wide range of adhesion strengths $\left(3 \times 10^{7} \mathrm{~Pa}\right.$ to $\left.3 \times 10^{9} \mathrm{~Pa}\right)$ have been measured, which are reproducible to $\pm 5 \%$. The lower limit can easily be extended in appropriate cases by using a point with a greater tip radius, but the upper limit is imposed by the strength of the substrates which tend to crack or splinter at higher loads.

Two recent improvements in the scratch technique should be noted. So for most of the work has been done on glass substrates because of the difficulties in observing clear channel on opaque substrates. Greene et $\mathrm{al}^{76}$ have developed a technique which is not limited by the optical transmission of the substrate, and thus extends the utility of the scratch test to all kinds of substrates. Secondly, in order to obtain the critical load, one has to make many scratches using increasing loads, but $\mathrm{Ahn}^{77}$ has indicated that all the requisite information can be derived by simply making one pass with programmed load.

4.2.2.5 Blister method In this test, a fluid - gas $^{78}$ or liquid $^{79}$ is injected beneath the coating at the coating-substrate interface and the hydrostatic pressure is increased until the coating begins to detach (peel away) from the interface. The beginning of the peel is usually indicated by discontinuity on the pressure-volume plot. Most of the work using this technique has been done on relatively thick $(25 \mu \mathrm{m})$ paint films. Dannenberg ${ }^{78}$ concluded that the technique was valid to surface coatings other than organic paints. For a recent theoretical analysis of blister test, the reader should refer to Williams. ${ }^{80}$ No reference could be found in the literature appertaining to the application of blister method to thin films. As the work required to detach metallic coatings will be considerably more than that for the 
K. L. MITTAL

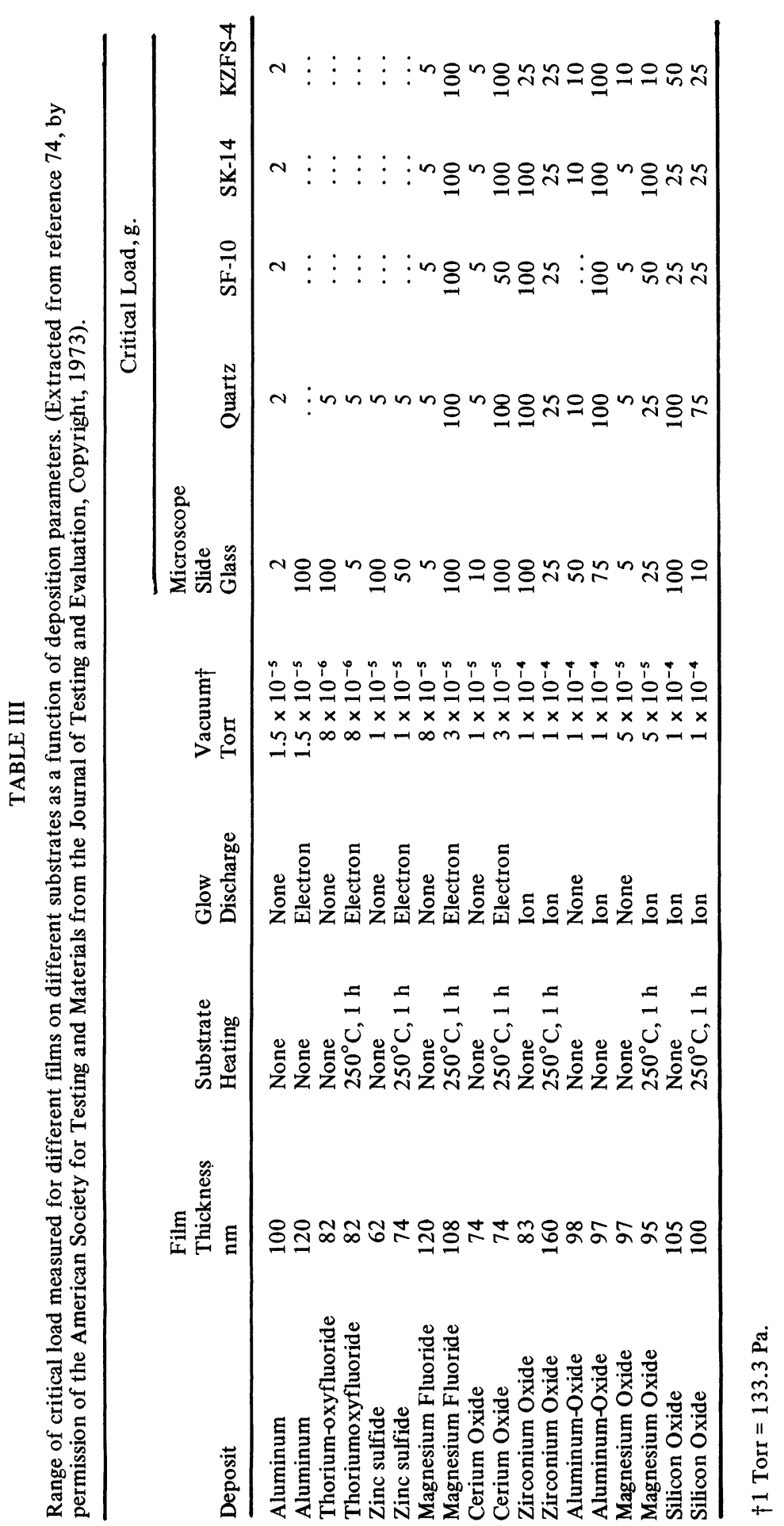


polymeric coatings, only less adherent metallic films may be amenable to this test. Furthermore, the values of adhesion strength thus determined will be influenced by the thickness, ductility, or brittleness of the film.

\subsection{Abrasion Method}

The abrasion resistance of films has received much attention and the literature can be traced back to 1930 , but in such studies the main objective was to determine the durability of the films, not adhesion per se. The abrasion resistance was determined by rubbing the surface with emery loaded rubber. ${ }^{81}$ However, a careful consideration will reveal that the abrasion resistance not only depends on the hardness of the film but it is influenced by the adhesion of the film to the substrate also.

This method has not gained much popularity and so the references to the use of this technique are scarce. Schossberger and Franson ${ }^{82}$ developed an abrasion-resistance test to study the adhesion of vacuum deposited aluminum films on glass surfaces. They used a stream of fine silicon carbide particles dropped from a known height to abrade the film and the removal of the film was monitored by measuring the electrical resistance of the film. By using this method they could detect differences in adhesion caused by the plating and annealing conditions. Poorest adhesion was found for platings made on unclean surfaces. The optimum substrate temperature for good adhesion was determined to be $175^{\circ} \mathrm{C}$.

The abrasion method, undoubtedly, involves burnishing as well as stripping action and these additional processes can certainly affect the values of adhesion obtained. In summary, this method certainly offers certain advantages but it has not found wide use as a practical method of obtaining quantitative adhesion values.

\subsection{Miscellaneous Techniques}

Under this heading are discussed those techniques which, at least at the present time, cannot be labelled as practical tests for measuring adhesion. Some tests are in a state of infancy but offer great potential, whereas others are of academic interest or are too elaborate. However, for completeness of this review, it is necessary to include these techniques also.

\subsubsection{Thermal method The principle of the} method is as follows: when a film is chemically dissolved from its substrate, the energy liberated is equal to the heat of solution of the film minus the energy of adhesion between the film and the substrate. A microcalorimeter ${ }^{83}$ is used to measure small heat changes. Apparently, only Chapman ${ }^{84}$ has employed this technique in the study of adhesion of vacuum deposited metallic films on $\mathrm{NaCl}$ substrate; and no other reference to the actual use of this technique could be found in the literature. Recently Chapman ${ }^{9}$ has indicated that there are experimental difficulties to be overcome in order to render this technique successful. As the liberated heat is very small, so the microcalorimeter in its present state may not offer a viable technique. The reader is referred to the original reference.

\subsubsection{X-ray method This is one of the} non-destructive methods of studying adhesion at the film-substrate interface. Chopra ${ }^{69}$ points out that the technique of X-ray topography can be employed to obtain qualitative information on the adhesion of epitaxial films deposited on single-crystal substrates ( $\mathrm{Si}$, for example). This is based upon the observation that the strains at the film substrate interface as well as the poor adhesion of the film modify the diffraction contrast of the substrate and thus provide qualitative information on strain and adhesion.

This method is applicable only in certain situations and cannot be generalized. Furthermore, no numerical values of adhesion of even epitaxial films can be obtained. However, it can be utilized as a comparative method for the adhesion of epitaxial films.

\subsubsection{Electron spin resonance method The} details of this technique are not available because of the lack of published material on this topic. Campbell ${ }^{7}$ reports on the basis of his private communication with Smith that this is one of the potential techniques for obtaining comparative measurements of adhesion. It appears that like the $\mathrm{X}$-ray method, this might be of limited applicability.

4.4.4 Capacitance method The details of this technique are not available to this author but the method is incorporated in this review with the assumption that one person's handicap may be another's standby. This method has been patented by Nekrasov $^{85}$. The details of this technique are taken from Bullett and Prosser ${ }^{6}$. In this method, an elastic electrode is placed on the coated metal panel and the absolute capacitance of the electrode so formed is measured at very low and very high frequencies. The ratio of the differences in capacitance to the 
capacitance at high frequency is claimed to give a co-efficient characteristic of the adhesion of the film. This co-efficient is an inverse measure of the adhesion of the film.

It is obvious that with the scanty details, it is not safe to appraise this method with respect to its applicability in determinimg quantitatively the adhesion of thin films.

\subsubsection{Cathodic treatment method Davies and} Whittaker ${ }^{4}$ have referred to this relatively old technique. In a sense, it is similar to the blister method (see above) with the difference that here hydrogen is used as the fluid to cause blistering. The method is based upon the following: The coated part is made the cathode in an electrochemical cell and the hydrogen evolved diffuses through the coating to collect at the interface and causes blistering. It is obvious that (1) this method has limited applicability as the substrate should be metal (2) it is qualitative (3) specific interaction between the film material and hydrogen evolved will affect the results. This method has not gained much attention as the original references date back to 1930's.

\subsubsection{Pulsed laser or electron-beam method}

Recently, a very interesting technique for the measurement of adhesion of thin films has been described by Anderson and Goodman ${ }^{86}$. The technique consists basically of generating a compressive pressure wave in the solid object of interest. The wave is next transferred by reflection into a tensile wave which then stresses the interface to be tested. The authors point out that such techniques have been used in the past for the dynamic tensile testing of bonds between two solids but their application to thin film adhesion was not mentioned. The actual description of the technique is as follows: A pulsed laser or a pulsed electron beam machine is used to deposit energy necessary to generate the compressive stress waves needed for the actual test. The first step is to prepare a substrate of a convenient size and then coat the desired area. The laser or electron beam machine is then used to bombard the remaining uncoated surface. The compressive wave which is generated propagates through the sample and is reflected from the coated surface which is left free. When the compressive wave reaches the free surface, it is reflected and inverted into a tensile wave of approximately the same amplitude. The amplitude of this resulting tensile wave can be altered by changing the initial energy input.
The authors point out that the determination of the actual adhesion strength involves considerable difficulties and they have not elaborated upon such problems. Furthermore, they have discussed the merits and demerits of this technique as regards the measurement of adhesion of thin films. The main disadvantage is that the technique is experimentally exacting and could prove prohibitively expensive under certain circumstances. In other words, the technique cannot be used generally. In summary, this method certainly offers some promise but considerable efforts must be spent to collect some numerical values of adhesion of thin films before it can be classified as a practical method for measuring adhesion.

\section{DISCUSSION AND CONCLUSIONS}

Ideally speaking, one would like to measure quantitatively the basic adhesion, i.e., adhesion due to intermolecular interactions between the film and the substrate. But as pointed out earlier, the experimentally measured adhesion strength consists of basic adhesion plus contribution from extraneous sources. These extraneous sources include the internal stresses in the film which always decrease the inherent adhesion strength, and the defects or extraneous processes introduced by the measuring procedure which may decrease the basic adhesion by introducing unmeasured stresses or may increase the basic adhesion by reducing the effects of internal stresses.

This can be expressed as

$$
\begin{aligned}
\text { Practical adhesion }= & \text { basic adhesion }- \text { (loss of } \\
& \text { adhesion due to internal stress }) \\
& \pm(\text { effects of defects or } \\
& \text { extraneous processes } \\
& \text { introduced by the test } \\
& \text { procedure }) .
\end{aligned}
$$

Furthermore, the nature and extent of the interfering processes differ from technique to technique, with the result that the practical adhesion values obtained by different techniques may not be directly comparable. In addition, the practical adhesion is measured either in terms of the force or the work required to disrupt unit area of the interface, and unless variation of the force with distance is known precisely, the values of practical adhesion expressed in the two different units cannot be directly relatable.

An ideal adhesion test should be (a) quantitative, (b) reproducible, (c) not very time consuming, (d) easily adaptable to routine testing, (e) relatively 
simple to perform, (f) nondestructive, (g) independent of the film thickness, (h) independent of the operator's experience, (i) applicable to all combinations of film materials and substrates, $(j)$ valid over a wide range of sample sizes, (k) applicable to products and processes, (1) independent of the manner of performing the test. Furthermore, no specialized test equipment should be necessary; but such idealization is not realized in practice as there is no technique which fulfills even half the above attributes. However the situation is not so hopeless, as many of the techniques have shown good promise, if certain conditions are fulfilled; furthermore, the lack of an ideal test should be an impetus for devising better techniques.

As is generally true, there are protagonists of each technique, but the following conclusions can easily be elicited from this review.

1) If no numerical values of adhesion are required then almost any of the techniques can be used to follow the changes in adhesion due to surface treatments, deposition variables, weathering, corrosive environment, ageing, etc.

2) The nucleation methods are not really the tests for measuring adhesion; the information derived from these has led to a better understanding of film formation and structure. These methods have limited applicability, are not valid for completed films, and require quite elaborate experimental set-up.

3) In the techniques where some sort of adhesive is used to glue the pulling device to pull the film, the following important points should be kept in mind: (1) The cohesive strength of the adhesive should be more than the adhesion between the film and the adhesive, and between the film and the substrate; (2) the adhesion between the adhesive and the film should be more than that between the film and the substrate; (3) the adhesive used should not alter the properties of the film-substrate interface; this might be less of a danger in metallic films, but the difficulties are aggravated when studying polymeric films.

In consideration of these undesirable aspects of gluing, ultracentrifugal and ultrasonic techniques offer certain advantages. With the new design of Dancy $^{35}$, where both ferro-magnetic and nonmagnetic substrates can be studied, the ultracentrifugal technique becomes very promising. It is generally believed that in this technique, a purely normal stress is applied to the film, but the situation is not so simple as commented by Huntsberger ${ }^{4}$. In the case of thin films, a high acceleration is required to provide the requisite ultracentrifugal stress, which means the choice of the rotor material and size becomes very critical, as the maximum acceleration which can be obtained is dictated by the bursting strength of the rotor. The new solid-state design should facilitate the use of this technique, provided due acceleration can be obtained. The ultrasonic technique certainly offers some desirable features and using piezoelectric transducers, one should be able to study adhesion of thin films. With suitable modifications, any substrate or film material can be studied.

4) Scotch tape test is too qualitative, small differences in adhesion are not discernible, and the interpretation of the results is quite subjective. The peel test is simple, requires modest equipment, but the analysis of the forces involved is quite complicated, and the angle of peel, rate of peel, width of the test strip, and the viscoelastic properties of the film are all very important. Furthermore, peel values expressed in force/length cannot be directly compared with the tensile or shear values which are recorded in terms of force/area.

Scratch or stylus test certainly offers many advantages as it is quick, reproducible, easy to perform, and it has been used quite profitably to investigate the effects of deposition variables, ageing, etc. However, the conversion of critical loads into quantitative values of adhesion may not be as straigthforward as discussed by Benjamin and Weaver ${ }^{63}$. Moreover, the findings of Oroshnik and Croll $^{73}$ that a complete removal of the film at the so called "critical load" is an infrequent event certainly shed a different light on the significance of critical load which has been used so frequently as a measure of adhesion. The scratch test is a very good technique but more investigation is needed to understand the detailed mechanics of scratch formation and the variables which affect the final results.

There are not many references to the tangential shear test but $\operatorname{Lin}^{57}$ has used it very recently and has claimed superiority of this method over the direct pull-off technique. More adhesion studies using this method are certainly needed.

Blister method has been used in case of relatively thicker polymeric coatings, but it should be applicable to thin polymeric films as well. The technique may not be suitable for the adhesion studies of metallic films. Abrasion test has not been popular in recent years, but the earlier studies certainly engender confidence in this method.

5) The tests covered under "Miscellaneous Tech- 
niques" are too narrow in scope and only sporadic references to their use could be found in the literature. The following points should be noted: (i) some of these are only qualitative, (ii) in some cases, specialized equipment is necessary, and (iii) some may simply detect voids or gaps which are manifestation of poor adhesion strength. The thermal method has been described and used by Chapman only ${ }^{84}$ and lately ${ }^{9}$ he has expressed the experimental difficulties involved in measuring very small heat changes with the existing microcalorimeters.

In the end, it should be added that in addition to improving upon the existing techniques or devising better means of measuring adhesion, more work is needed in these two areas: (i) Cross comparison of various techniques. Various substrate-film combinations should be tested for adhesion by different techniques. (ii) Adhesion measurement of thin polymeric films. The time dependent and viscoelastic behavior of polymeric films may invalidate or complicate the usefulness of certain techniques which are quite valid in the case of metallic films. So a detailed inquiry into the effects of these and other characteristics of polymeric films on their adhesion strength should be conducted.

\section{REFERENCES}

1. A. W. Henderson, Adhesion in electronics, in Aspects of Adhesion, Vol. 5, D. J. Alner, Editor, pp. 86-104, CRC Press, Cleveland, Ohio, 1969.

2. C. Weaver, Adhesion of thin films, Proc. of the First International Conference on Vacuum Techniques, Namur, 2, 734-736 (1958), Pergamon Press, London, England, (1960).

3. C. Weaver, The adhesion of metal films to surfaces, Chem. Ind., 370-373, February 27, 1965.

4. D. Davies and J. A. Whittaker, Methods of testing the adhesion of metal coatings to metals, Metallurgical Reviews 12, 15-26 (1967).

5. D. G. Williams, The adhesion of vacuum-deposited films, A Technical Report from Dow Chemical U.S.A., Rocky Flats Division, P.O. Box 888, Golden, Colorado. Under U.S. Atomic Energy Commission Contract AT (29-1) -1106 , RFP-1690, July 21, 1972, 17 pages.

6. T. R. Bullett and J. L. Prosser, The measurement of adhesion, Prog. Org. Coatings 1, 45-73 (1972).

7. D. S. Campbell, Mechanical properties of thin films, in Handbood of Thin Film Technology, L. I. Maissel and R. Glang, Editors, Chapter 12, McGraw Hill Book Company, N. Y., 1970.

8. K. L. Mittal, A critical appraisal of the methods for measuring adhesion of electrodeposited coatings, in Properties of Electrodeposits: Their Measurement and Significance, R. Sard, H. Leidheiser, Jr., and F. Ogburn, Editors, Chap. 17, pp. 273-306, The Electro-chemical Society, Princeton, N.J. (1975).
9. B. N. Chapman, Thin-film adhesion, J. Vac. Sci. Tech. 11 106-113 (1974).

10. C. Weaver, Adhesion of thin films, J. Vac. Sci. Tech. 12, 18-25 (1975).

11. G. Salomon, in Adhesion and Adhesives, Vol. 1, p. 3, R. Houwink and G. Salomon, Editors, Elsevier Publishing Co., New York, 1965.

12. R. J. Good, On the definition of adhesion, J. Adhesion, in press.

13. D. Taylor, Jr. and J. E. Rutzler, Jr., Adhesion using molecular models, Ind. Eng. Chem. 50, 928-934 (1958).

14. R. J Good Intermolecular and interatomic forces, in Treatise on Adhesion and Adhesives, Vol. 1, Chap. 2 pp. 9-68, R. L. Patrick, Editor, Marcel Dekker, Inc., New York, 1967.

15. W. A. Zisman, Relation of the equilibrium contact angle to liquid and solid constitution, in Advances in Chemistry Series No. 43, pp. 1-51, American Chemical Society, Washington, D.C., 1964.

16. K. L. Mittal, Surface chemical criteria for maximum adhesion and their testing against the published experimental adhesive strength values, in Adhesion Science and Technology, vol. 9A, pp. 129-168, L. H. Lee, Editor, Plenum Press, New York, 1975.

17. P. Benjamin and C. Weaver, Condensation energies for metals on glass and other substrates, Proc. Roy. Soc A252, 418-430 (1959).

18. B. N. Chapman, Adhesion of thin metallic films, in Aspects of Adhesion Vol. 6, pp. 43-54, D. J. Alner, Editor, CRC Press, Cleveland, Ohio, 1971

19. R. B. Belser and W. H. Hicklin, Simple rapid sputtering apparatus, Rev. Sci. Instrum. 27, 293-296 (1956).

20. R. B. Belser, Aging study of metal plating on quartz crystals, Report No. AD48261, Defense Document Center, Wash., D.C., 1954.

21. J. R. Frederick and K. C. Ludema, Adhesion of vapor-deposited aluminum to lime-soda glass, J. Appl. Phys. 35, 256-257 (1964).

22. R. L. Beno, An adhesion tester for evaporated metal films, U.S. Atomic Energy Commission Contract AT (29-1) -1106, R.F.P. -672, January 11, 1966.

23. Y. Chiang and S. W. Ing, Interface and adhesion studies on evaporated selenium on oxide surfaces, J. Vac. Sci. Tech. 6, 809-814 (1969).

24. L. E. Collins, J. G. Perkins and P. T. Stroud, Effect of ion bombardment on the adhesion of aluminum films on glass, Thin Solid Films. 4, 41-45 (1969).

25. K. Kuwahara, T. Nakagawa and K. Kuramasu, Effect of ion-pump evacuation on the adhesion of evaporated thin films. Japanese Inst. Metals Trans. 12, 218-219 (1971).

26. M. J. Hardon and M. A. Wright, High vacuum adhesion test apparatus, Rev. Sci. Instrum. 40, 1017-1021 (1969).

27. R. Jacobsson and B. Kruse, Measurement of adhesion of thin evaporated films on glass substrates by means of direct pull off method, Thin Solid Films 15, 71-77 (1973).

28. S. D. Cramer, et al., Measuring electrodeposit adhesion, Metal Finishing, 45-50 (March 1970).

29. D. W. Butler, A simple film adhesion comparator, $J$. Phys. (E) Sci. Instrum. 8, 979-980 (1970).

30. D. W. Butler, C. T. H. Stoddart and P. R. Stuart, Some factors affecting the adhesion of thin metal films, in Aspects of Adhesion Vol. 6 pp. 53-63, D. J. Alner, Editor, CRC Press, Cleveland, Ohio, 1971. 
31. C. T. H. Stoddart, D. R. Clarke and C. J. Robbie, Thin film adhesion: Effect of glow discharge on substrate, $J$. Adhesion 2, 270-278 (1970).

32. K. Wieckowski, Conductive thin films, Pr. Nauk. Inst. Technol. Electron Politekh Wroclaw No. 7,7-16 (1972).

33. F. D. Hallworth, Bond testing of silver-plated engine bearings, Automotive and Aviation Ind. 95(2), $30-(1946)$

34. a) J. W. Beams, Production and use of high centrifugal fields, Science 120, 619-625 (1954).

b) J. W. Beams, J. Breazeale and W. L. Bart, Mechanical strength of thin films of metal, Phys. Rev. 100, 1657-1661 (1955).

c) J. W. Beams, Study of adhesion by the high-speed rotor technique, Tech. Proc. Amer. Electroplaters Soc. 43, 211-214 (1956).

35. W. H. Dancy, Jr., A solid state ultracentrifuge for adhesion testing of electrodeposits, Technical Report RE 701-138, April 1970, 58 pp. AD 752 460, available NTIS.

36. 1975 Guiness Book of World Records. Norris McWhirter and Ross McWhirter, Editors, p. 185, Bantam Books, New York, 1975.

37. W. H. Dancy, Jr. and A. Zavarella, Adhesion of chromium and other deposits to steel, Plating 52, 1009-1016 (1965).

38 V. M. Ponizovskii, Yu. G. Svetlov and G. V. Chirkov, Determination of adhesion of copper and nickel coatings on a steel base by means of large centrifugal fields, Zashch Metal 3(4), 515-517 (1967); Chemical Abstracts $68,42493 X$ (1967).

39. V. M. Ponizovskii and G. P. Spelkov, Determination of the strength of the adherence of chromium electroplate on steel by a high centrifugal field method, Zavod Lab. 40(1), 107-109 (1974); Chemical Abstracts 80, 127398t (1974).

40 A. M. Malloy, W. Soller and A. G. Roberts, Evaluation of adhesion of organic coatings by ultracentrifugal and other methods - Part 1, Paint Oil \& Chem. Rev., pp. 14-19, August 27, 1953.

41. H. Alter and W. Soller, Ultracentrifugal measurement of the adhesion of epoxy polymer, Ind. Eng. Chem. 50, 922-927 (1958).

42. R. L. Patrick, W. A. Vaughan and C. M. Doede, The ultracentrifuge as an Instrument for testing adhesion, J. Polymer Sci. 28, 11-16 (1958).

43. J. R. Huntsberger, Influence of selective adsorption on adhesion, J. Polymer Sci. 43, 581-582 (1960).

44. J. R. Huntsberger, Ultracentrifugal measurement of adhesion: some limitations, Official Digest 33, 635(1961).

45. V. M. Ponizovskii, et al., Determination of the adhesion of coatings to steel . . . centrifugal force, Lakokrasoch Mater. Ikh Primen No. 5, 52-54 (1972); Chemical Abstracts 78, 85996n (1973).

46. S. Moses and R. K. Witt, Evaluation of adhesion by ultrasonic vibrations, Ind. Eng. Chem. 41, 2334-2338 (1949).

47. S. Moses, The nature of adhesion, Ind. Eng. Chem. 41, 2338-2342 (1949).

48. R. Faure, A. Carlan, J. Crebassa, G. Desvousseaux and B. Robrieux, Modification de la structure des couches minus d'argent soumiser a des vibrations mechaniques measure de l'adhesion, Thin Solid Films 9, 329-339 (1972).
49. J. Strong, Evaporated aluminum films for astronomical mirrors, Publ. A.S.P. 46, 18 (1934).

50. J. Strong, On the cleaning of surfaces, Rev. Sci. Instrum. 6, 97-98 (1935).

51. R. C. Willians and R. C. Backus, The electronmicrographic structure of shadow-cast films and surfaces, J. Appl. Phys. 20, 98, 106 (1949).

52. K. E. Haq, K. H. Behrndt and I. Kobin, Adhesion mechanism of gold-underlayer film combinations to oxide substrates, J. Vac. Sci. Tech. 6, 148-152 (1969).

53. D. M. Mattox and J. E. McDonald, Interface formation during thin film deposition, J. Appl. Phys. 34, 2493-2494 (1963).

54. R. C. Sundhal, Relationship between substrate surface chemistry and adhesion of thin films, J. Vac. Sci. Tech. 9, 181-185 (1972).

55. W. T. Chen and T. F. Flavin, Mechanics of film adhesion elastic and elastic-plastic behavior, IBM Journal of $R \& D$. 16, No. 3, 203-213 (1972).

56. N. M. Poley and H. L. Whitaker, Adhesion of chromium films to soda lime glass, J. Vac. Sci. Tech. 11, 114-118 (1974).

57. D. S. Lin, The adhesion of metal films to glass and magnesium oxide in tangential shear, J. Physics $(D)$ : Appl. Phys. 4, 1977-1990 (1971).

58. J. W. Dini, J. R. Helms and H. R. Johnson, Ring shear test for quantitatively measuring adhesion of metal deposits, Electroplating Metal Finish. 25, 5-11 (1972).

59. J. W. Dini and H. R Johnson, Ring shear adhesion tests various deposit - substrate combinations, Metal Finish. pp. 44-48 (Aug. 1974).

60. O.S. Heavens, Some factors influencing the adhesion of films produced by vacuum evaporation, J. Phys. Radium 11, 355-360 (1959).

61. O.S. Heavens and L. E. Collins, L'epitaxie dans les lames polycrystallines, J. Phys. Radium 13, 658-660 (1952).

62. C. Weaver and R. M. Hill, Adhesion of evaporated aluminum films, Phil. Mag. 3, 1402-1410 (1958).

63. P. Benjamin and C. Weaver, Measurement of adhesion of thin films, Proc. Roy. Soc. 254A, 163-176 (1960).

64. P. Benjamin and C. Weaver, Adhesion of metal films to glass, Proc. Roy. Soc. 254A, 177-183 (1960) .

65. P. Benjamin and C.Weaver, The adhesion of evaporated metal film on glass, Proc. Roy. Soc. 261A, 516-531 (1961).

66. P. Benjamin and C. Weaver, The adhesion of metals to crystal faces, Proc. Roy. Soc. 274A, 267-273 (1963).

67. C. Weaver, Adhesion of high energy surfaces, in Adhesion Fundamentals and Practice, pp. 46-57, Maclaren \& Sons Ltd., London, 1969.

68. C. Weaver and D. J. Parkinson, Diffusion in goldaluminum, Phil. Mag. 22, 377-389 (1970).

69. K. L. Chopra, Thin Film Phenomena, pp. 313-323, McGraw-Hill Book Company, N.Y., 1969.

70. D. W. Butler, C. T. H. Stoddart and P. R. Stuart, The stylus or scratch method for thin film adhesion measurement: some observations and comments, J. Physics (D): Appl. Phys. 3, 877-883 (1970).

71. M. M. Karnowsky and W. B. Estill, Scratch test for measuring adherence of thin films to oxide substrates, Rev. Sci. Instrum. 35, 1324-1326 (1964).

72. J. Hamersky, Feststellung optimaler Parameter bei Adhasionsmessungen unter Anwendung der Ritzmethode, Thin Solid Films 3, 263-267 (1969). 
73. J. Oroshnik and W. K. Croll, Thin film adhesion testing by the scratch method, paper presented at the Surface Science Symposium of the New Mexico Section of the American Vacuum Society, held in Albuquerque, N.M., April 22, 1970.

74. A. T. English and P.A. Turner, Stability of conductor metallization in corrosive environments, J. Electronic Materials 1, 1-14 (1972).

75. O. Berendsohn, Quantitative adhesion tests of vacuum deposited thin films, J. Testing Evaluation 1, 139-143 (1973).

76. J. E. Greene, J. Woodhouse and M. Pestes, A technique for detecting critical loads in the scratch test for thin film adhesion, Rev. Sci. Instrum. 45, 747-749 (1974).

77. J. Ahn, personal communication, 1974.

78. E. Hoffman and O. Geogoussis, Measurement of adhesion of paint films, J. Oil. Color. Chem. Assoc. 42, 267-269 (1959).

79. H. Dannenberg, Measurement of adhesion by a blister method, J. Appl. Polymer Sci. 5, 125-134 (1961).
80. M. L. Williams, The continuum interpretation for fracture and adhesion, J. Appl. Polymer Sci. 13, 29(1969).

81. L. Holland, Vacuum Deposition of Thin Films, pp. 88-103, Chapman \& Hall Ltd., London, 1956.

82. F. Schossberger and K. D. Franson, Adhesion of evaporated metal films, Vacuum 9, 28-35 (1959).

83. E. Calvet and H. Prat, Recent advances in Microcalorimetry, Pergamon Press, N.Y., 1963.

84. B. N. Chapman, The adhesion of thin films, Ph.D. Thesis Electrical Eng. Dept. Imperial College, London, 1969.

85. M. M. Nekrasov, U.S.S.R. Patent 127063.

86. N. C. Anderson and A. Goodman, A technique for measuring the adhesion of thin films and the dynamic tensile strength of bonds, with commercial applications, Technical Report Published from Sandia Laboratories, Albuquerque, New Mexico, March 1972, 7 pages. The Report is available from NTIS under number SC-DR-69-320.

\section{Appendix}

\section{SOME CONVERSION FACTORS AND UNITS COMMONLY USED TO EXPRESS ADHESION STRENGTH}

$\begin{aligned} 1 \mathrm{~Pa}(\text { Pascal) } & =10 \mathrm{dyn} \mathrm{cm}^{-2} \\ \left.\quad \text { (i.e., } 1 \mathrm{~N} \mathrm{~m}^{-2}\right) & =1.4504 \times 10^{-4} \mathrm{psi} \\ & =1.4504 \times 10^{-2} \mathrm{gf} \mathrm{cm}^{-2} \\ & =1.0197 \times 10^{-2} \mathrm{gf} \mathrm{cm}^{-2} \\ & =1.0197 \times 10^{-5} \mathrm{kgf} \mathrm{cm}^{-2} \\ & =1.0197 \times 10^{-1} \mathrm{~kg} \mathrm{~m}^{-2} \\ & =1.0197 \times 10^{-7} \mathrm{kgf} \mathrm{mm}^{-2} \\ & =10 \mu \mathrm{bar} \\ & =7.5 \times 10^{-3} \mathrm{Torr} \\ & =0.9872 \times 10^{-5} \text { Atmosphere } \\ 1 \mathrm{~kg} \mathrm{~cm}^{-1} & =5.61 \mathrm{~b} . \mathrm{in}^{-1} \\ 1 \mathrm{~J} \mathrm{~m}^{-2} & =10^{3} \mathrm{erg} \mathrm{cm} \\ 1 \mathrm{~N} & =10^{5} \mathrm{dyn} \\ 1 \mathrm{Torr} & =1 \mathrm{~mm}(\mathrm{Hg})=133.3 \mathrm{~Pa}\end{aligned}$



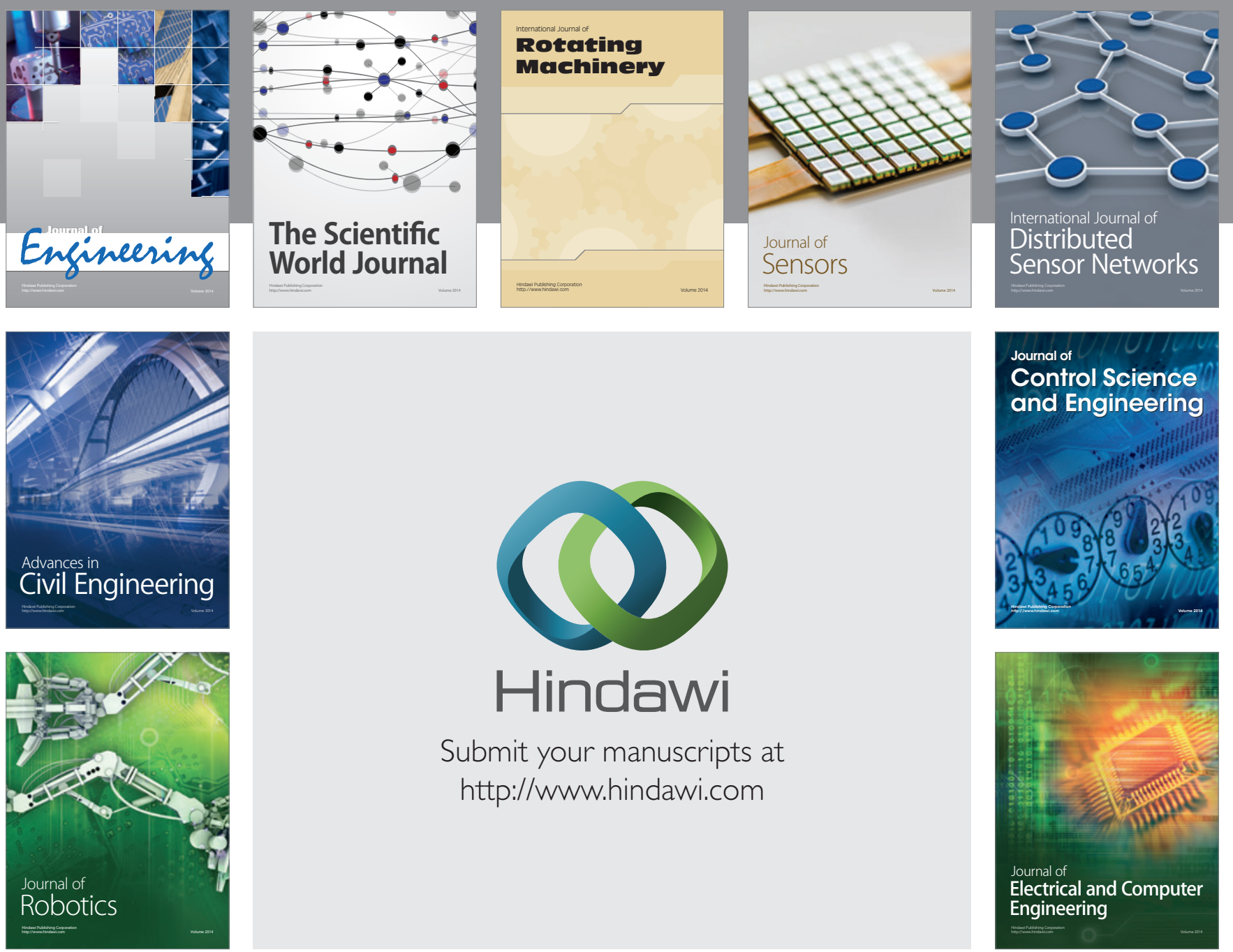

Submit your manuscripts at

http://www.hindawi.com
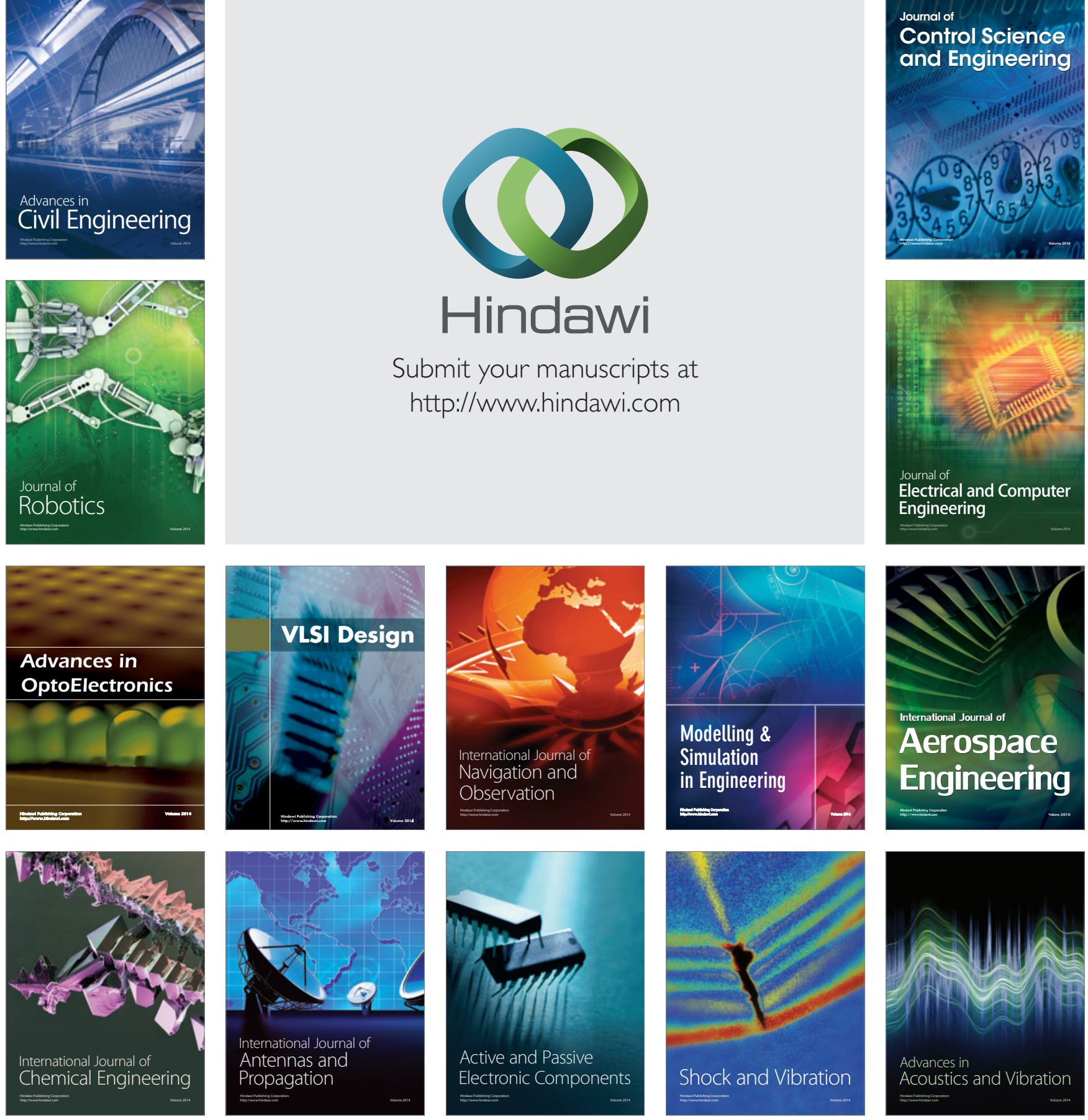